\title{
L-threonine transaldolase activity is enabled by a persistent
}

\section{catalytic intermediate}

Prasanth Kumar ${ }^{\mathrm{a}, \star}$, Anthony Meza ${ }^{\mathrm{b}, \star}$, Jonathan M. Ellis ${ }^{\mathrm{a}}$, Grace A. Carlson ${ }^{\mathrm{a}}$, Craig A. Bingman ${ }^{\mathrm{b}}$, Andrew R. Buller ${ }^{\mathrm{a}, \mathrm{b}, *}$

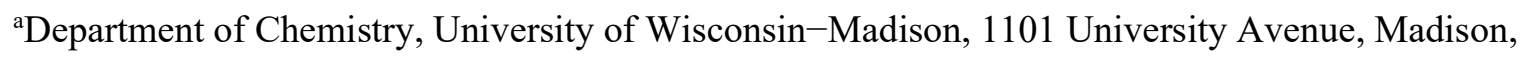
Wisconsin 53706, United States

${ }^{\mathrm{b}}$ Department of Biochemistry, University of Wisconsin-Madison, 1101 University Avenue, Madison, Wisconsin 53706, United States

¥These authors contributed equally

*To whom correspondence should be addressed: Andrew R. Buller (arbuller@wisc.edu)

\section{Supporting Information}




\section{SI Table of Contents}

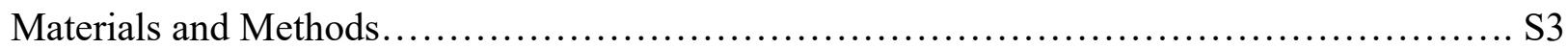

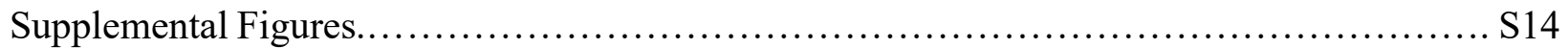

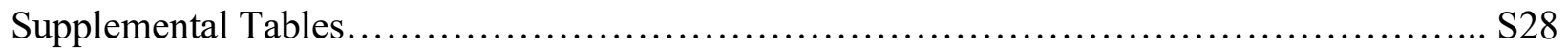

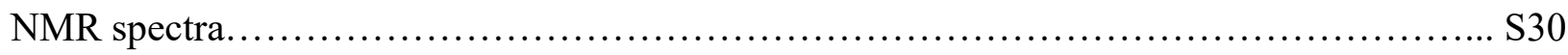

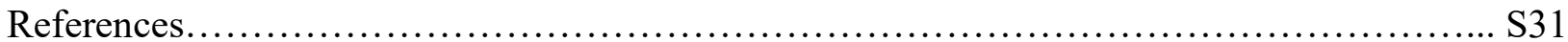




\section{Materials and methods}

\section{General experimental procedures}

Chemicals and reagents were purchased from commercial suppliers (Sigma-Aldrich, VWR, Chem-Impex International, Combi-blocks, Alfa Aesar, New England Biolabs, Zymo Research, Bio-Rad) and used without further purification unless otherwise noted. BL21 (DE3) E. coli cells were electroporated with a Bio-Rad MicroPulser electroporator at $2500 \mathrm{~V}$. New Brunswick I26R, $120 \mathrm{~V} / 60 \mathrm{~Hz}$ shaker incubators (Eppendorf) were used for cell growth. Optical density and UV-vis measurements were collected on a UV2600 Shimadzu spectrophotometer (Shimadzu). UPLC-MS data were collected on an Acquity UHPLC with an Acquity QDa MS detector (Waters) using an ACQUITY UPLC CSH BEH C18 column (Waters) or an Intrada Amino Acid column (Imtakt). Preparative flash chromatographic separations were performed on an Isolera One Flash Purification system (Biotage). Proton NMR spectra were recorded on a Bruker AVANCE III-500 MHz spectrometer equipped with a DCH cryoprobe. Proton chemical shifts are reported in ppm $(\delta)$ relative to the solvent resonance $\left(\mathrm{D}_{2} \mathrm{O}, \delta 4.79 \mathrm{ppm}\right)$. Data are reported as follows: chemical shift (multiplicity [singlet (s), doublet (d), doublet of doublets (dd), multiplet (m)], coupling constants [Hz], integration). All NMR spectra were recorded at ambient temperature (about $25^{\circ} \mathrm{C}$ ).

\section{Cloning, expression, and purification of ObiH}

A codon-optimized copy of the ObiH gene was purchased as a gBlock from Integrated DNA Technologies. This DNA fragment was inserted into a pET-28b(+) vector by the Gibson Assembly method. ${ }^{1}$ BL21 (DE3) E. coli cells were subsequently transformed with the resulting cyclized DNA product via electroporation. After 45 min of recovery in Luria-Burtani (LB) media containing $0.4 \%$ glucose at $37^{\circ} \mathrm{C}$, cells were plated onto LB plates with $50 \mu \mathrm{g} / \mathrm{mL}$ kanamycin (Kan) and incubated overnight. Single colonies were used to inoculate $5 \mathrm{~mL} \mathrm{LB}+50 \mu \mathrm{g} / \mathrm{mL} \mathrm{Kan}$, which were grown overnight at $37^{\circ} \mathrm{C}, 200 \mathrm{rpm}$. Expression cultures, typically $1 \mathrm{~L}$ of Terrific Broth (TB) $+50 \mu \mathrm{g} / \mathrm{mL}$ Kan (TB-Kan), were inoculated from these starter cultures 
and shaken $(180 \mathrm{rpm})$ at $37^{\circ} \mathrm{C}$. After 3 hours $\left(\mathrm{OD}_{600}=\sim 0.6\right)$, the expression cultures were chilled on ice. After $30 \mathrm{~min}$ on ice, ObiH expression was induced with $0.5 \mathrm{mM}$ IPTG, and the cultures were expressed for 16 hours at $20^{\circ} \mathrm{C}$ with shaking at $180 \mathrm{rpm}$. Cells were then harvested by centrifugation at $4,300 \times g$ at $4{ }^{\circ} \mathrm{C}$ for $30 \mathrm{~min}$. Cell pellets were pink in color and were frozen and stored at $-20{ }^{\circ} \mathrm{C}$ until purification.

To purify ObiH, cell pellets were thawed on ice and then resuspended in lysis buffer (50 mM potassium phosphate buffer buffer ( $\mathrm{pH}=8.0), 500 \mathrm{mM} \mathrm{NaCl}, 1 \mathrm{mg} / \mathrm{ml}$ Hen Egg White Lysozyme (GoldBio), 0.2 $\mathrm{mg} / \mathrm{ml}$ DNaseI (GoldBio), 1 mM MgCl 2,1 X BugBuster Protein extraction reagent (Novagen), and $400 \mu \mathrm{M}$ pyridoxal 5'-phosphate (PLP)). A volume of $4 \mathrm{~mL}$ of lysis buffer per gram of wet cell pellet was used. After 45 min of shaking at $37^{\circ} \mathrm{C}$, the resulting lysate was then spun down at $75,600 \times g$ to pellet cell debris. The pellet was colorless whereas the supernatant was pink in color. Ni/NTA beads (GoldBio) were added to the supernatant and incubated on ice for 45 min prior to purification by Ni-affinity chromatography with a gravity column. The column was washed with 5 column volumes of $20 \mathrm{mM}$ imidazole, $500 \mathrm{mM} \mathrm{NaCl}, 10 \%$ glycerol, $50 \mathrm{mM}$ potassium phosphate buffer $(\mathrm{pH}=8.0)$. Washing with higher concentrations of imidazole resulted in slow protein elution. ObiH was eluted with $250 \mathrm{mM}$ imidazole, $500 \mathrm{mM} \mathrm{NaCl}, 10 \%$ glycerol, $50 \mathrm{mM}$ potassium phosphate buffer, $\mathrm{pH}$ 8.0. Elution of the desired protein product was monitored by the disappearance of its bright red color (resulting from the release of $\mathrm{ObiH}$ ) from the column. The protein product was dialyzed to $<1 \mu \mathrm{M}$ imidazole in $100 \mathrm{mM}$ Tris buffer, $\mathrm{pH} 8.5$ containing $2 \mathrm{mM}$ DTT, dripped into liquid nitrogen to flash freeze, and stored at $-80{ }^{\circ} \mathrm{C}$ before use. The concentration of protein was determined by Bradford assay. Generally, this procedure yielded 200 - $250 \mathrm{mg}$ per L culture. E107Q and D204N variants were purified similar to that of wt-ObiH.

\section{Preparation of phototreated ObiH}

ObiH stock solutions $(150-400 \mu \mathrm{M})$ or diluted samples in quartz cuvettes were placed on ice directly under an 8 Watt, green LED bulb for $10 \mathrm{~min}$. The protein solutions were subsequently kept on ice or in the 
UV-spectrophotometer for $45 \mathrm{~min}$, followed by a second round of green light treatment for 10 minutes which ensured complete abolishment of the $515 \mathrm{~nm}$ band.

\section{Kinetics and UV-Vis Spectroscopy}

Data were collected between 600 and $250 \mathrm{~nm}$ on a UV-2600 Shimadzu spectrophotometer (Shimadzu) with a semi-micro quartz cuvette (Starna Cells) at $25{ }^{\circ} \mathrm{C}$ (unless stated otherwise). ObiH stock solutions were diluted to $20 \mu \mathrm{M}$ in $100 \mathrm{mM}$ Tris-HCl, pH 8.5 and phototreated. For the Thr titration, a $500 \mathrm{mM}$ Thr solution was prepared in $100 \mathrm{mM}$ Tris- $\mathrm{HCl}, \mathrm{pH} 8.5$ to ensure consistent $\mathrm{pH}$ between titration experiments. Thr was added to the concentrations of 10, 50,100,150, and $200 \mathrm{mM}$. Time in seconds was recorded from addition of Thr to the time at which data collection at $493 \mathrm{~nm}$ occurred. Spectra from $600-250 \mathrm{~nm}$ were collected every 200 seconds for $2.5 \mathrm{~h}$. All 5 concentrations were conducted at one time using an automated cell changer. A first order decay constant was fit to the data from $33-150 \mathrm{~min}$. Decay constants for experiments with $\mathrm{Thr}>100 \mathrm{mM}$ were averaged to estimate the half-life of $\mathrm{E}\left(\mathrm{Q}^{\mathrm{Gly}}\right)$. To monitor the aldol addition of aliphatic aldehyde to $\mathrm{E}\left(\mathrm{Q}^{\mathrm{Gly}}\right), 20 \mu \mathrm{M}$ ObiH samples were prepared in $100 \mathrm{mM}$ Tris-HCl, $\mathrm{pH} 8.5$ and phototreated. $100 \mathrm{mM}$ Thr was added and spectra were gathered while the $E\left(Q^{\mathrm{Gly}}\right)$ species reached a maximum (generally after $\sim 10 \mathrm{~min}$ ). Aliphatic aldehyde stocks were prepared as $500 \mathrm{mM}$ solutions in DMSO. Aldehydes were added to final concentration of $25 \mathrm{mM}, 5 \%$ DMSO. Spectra were recorded every $1 \mathrm{~min}$ from $600-250 \mathrm{~nm}$. To monitor equilibrium between acetaldehyde and $\mathrm{E}\left(\mathrm{Q}^{\mathrm{Gly}}\right), 20 \mu \mathrm{M}$ ObiH samples were prepared in $100 \mathrm{mM}$ Tris-HCL, pH 8.5 and phototreated. $100 \mathrm{mM}$ Thr was added and spectra were gathered while the $\mathrm{E}\left(\mathrm{Q}^{\mathrm{Gly}}\right)$ species produced a strong signal. Acetaldehyde stock solutions were added 5 minutes after the addition of Thr and spectra were collected every minute for 15 minutes. 20X acetaldehyde solutions were prepared in DMSO to ensure each experiment contained 5\% DMSO (500 mM, $200 \mathrm{mM}$, $100 \mathrm{mM}, 20 \mathrm{mM}$, and $4 \mathrm{mM}$ in DMSO). To monitor product reentry, $20 \mu \mathrm{M}$ ObiH samples were prepared in 100 mM Tris-HCl, pH 8.5 and phototreated. Purified $\beta-O H-L e u$ stocks were prepared in water $(100 \mathrm{mM})$.

Products were added to a final concentration of $20 \mathrm{mM}$ and spectra were gathered every 1 minute. A small 
background PLP contamination was noted for $\beta-\mathrm{OH}-\mathrm{Leu}$. To account for this absorbance from PLP, a spectrum of $20 \mathrm{mM} \beta-\mathrm{OH}-\mathrm{Leu}$ in $100 \mathrm{mM}$ Tris- $\mathrm{HCl}$ was gathered and subtracted from the plus enzyme spectrum. To assess whether glycine can form $\mathrm{E}\left(\mathrm{Q}^{\mathrm{Gly}}\right), 2.0 \mathrm{M}$ solution of glycine was prepared in $100 \mathrm{mM}$ Tris-HCl, pH 8.5. $20 \mu \mathrm{M}$ ObiH samples were prepared in $100 \mathrm{mM}$ Tris-HCl, $\mathrm{pH} 8.5$ and phototreated. Glycine was added to a final concentration of $1.0 \mathrm{M}$. Spectra from $600-250 \mathrm{~nm}$ were gathered every 1 minute. $\underline{\mathrm{NaBH}}_{4}$ reduction experiments were conducted with phototreated and as-isolated ObiH. $20 \mu \mathrm{M}$ samples of $\mathrm{ObiH}$ were prepared in $100 \mathrm{mM}$ Tris-HCl, $\mathrm{pH}$ 8.5. $100 \mathrm{mM}$ Thr was added and spectra were gathered while the $\mathrm{E}\left(\mathrm{Q}^{\mathrm{Gly}}\right)$ species reached a maximum. A fresh solution of $200 \mathrm{mM} \mathrm{NaBH}_{4}$ was prepared in $\mathrm{H}_{2} \mathrm{O}$ and added to the reaction mixture to a final concentration of $2 \mathrm{mM} 10$ minutes after the addition of Thr. Spectra were gathered from 600 - $250 \mathrm{~nm}$ every 1 minute. UV-vis experiments for E107Q and D204N variants were performed similar to that of the wild-type protein.

\section{Initial velocity comparison between phototreated and as-purified ObiH}

ObiH was thawed and centrifuged at $20,000 \times g$ for $20 \mathrm{~min}$ to pellet aggregated protein. The resulting supernatant was split into two separate tubes and kept on ice. One sample was wrapped in foil to preserve the $515 \mathrm{~nm}$ species while the other underwent phototreatment (10 min green light, $45 \mathrm{~min}$ on ice, $10 \mathrm{~min}$ green light). Reactions were prepared in $100 \mathrm{mM}$ Tris- $\mathrm{HCl}$, pH 8.5 with $100 \mathrm{mM}$ Thr, $25 \mathrm{mM}$ isobutryaldehyde, $20 \mu \mathrm{M}$ ObiH, and $100 \mu \mathrm{M}$ PLP in triplicate. Reaction mixtures were pre-incubated in a water bath at $37^{\circ} \mathrm{C}$ prior to addition of enzyme. After addition of $\mathrm{ObiH}, 20 \mu \mathrm{L}$ of reaction mixture was removed and quenched with $20 \mu \mathrm{L}$ of acetonitrile at 2, 5, 10, 15, and $30 \mathrm{~min}$. Quenched reactions were centrifuged at $20,000 \times \mathrm{g}$ for $20 \mathrm{~min}$ to pellet aggregated protein. Supernatant was diluted 10 -fold into a 1:1 $\mathrm{H}_{2} \mathrm{O}$ :acetonitrile solution and analyzed via UPLC-MS for product quantification. Reaction mixtures progressed overnight and a reaction sample was taken at 24 hours for additional quantification. 


\section{Preparative scale synthesis of $(2 S, 3 R)-\beta$-hydroxyleucine}

ObiH was thawed and centrifuged at $20,000 \times g$ for 20 min to pellet aggregated protein. Protein stock concentration was obtained using the Bradford assay on a representative sample. Thr (1.19 $\mathrm{g}, 10 \mathrm{mmol})$, isobutyraldehyde (0.361 g, $5 \mathrm{mmol}), 5 \mathrm{~mL} \mathrm{MeOH}$, and $\sim 85 \mathrm{~mL}$ with $100 \mathrm{mM}$ Tris-HCl, pH 8.5 buffer were added to a $100 \mathrm{~mL}$ round bottom flask. Pyridoxal-5'-phosphate was added to a final concentration of 100 $\mu \mathrm{M}$, followed by $\mathrm{ObiH}$ to a final concentration of $20 \mu \mathrm{M}(0.04 \mathrm{~mol} \%$ catalyst $)$. The reaction mixture was incubated for $24 \mathrm{~h}$ at $37^{\circ} \mathrm{C}$. The reaction mixture was then heated to $70^{\circ} \mathrm{C}$ for 30 minutes to denature $\mathrm{ObiH}$. The reaction mixture was transferred to $50 \mathrm{~mL}$ conical vials and centrifuged at $4,300 \times \mathrm{g}$ for 10 minutes to pellet aggregated protein. The supernatant was transferred to $500 \mathrm{~mL}$ round bottom flask and concentrated by rotary evaporation. For purification, $1 / 2$ of the resulting reaction mixture was loaded onto a Biotage SNAP Ultra $12 \mathrm{~g} \mathrm{C18}$ column and purified on a Biotage flash purification system using a water/methanol gradient. Fractions were analyzed by UPLC-MS to identify product containing fractions. Fractions containing pure product were set aside. Fractions containing both Thr and product were pooled, concentrated, and subjected to a second round of chromatography. All pure product containing fractions from both rounds of purification were then pooled, concentrated by rotary evaporation, and dried via lyophilization (141 mg, 38\%). ${ }^{1} \mathrm{H}$ NMR (500 MHz, $\left.\mathrm{D}_{2} \mathrm{O}\right) \delta 3.743(\mathrm{~s}, 1 \mathrm{H}), 3.736(\mathrm{dd}, \mathrm{J}=3.8,10.6 \mathrm{~Hz}, 1 \mathrm{H}), 1.78(\mathrm{~m}, \mathrm{~J}=6.74 \mathrm{~Hz}$, $1 \mathrm{H}), 1.03(\mathrm{~d}, \mathrm{~J}=6.59,1 \mathrm{H}), 0.98(\mathrm{~d}, \mathrm{~J}=6.78,1 \mathrm{H})$

\section{Crystallization and structural studies of ObiH}

Crystallization conditions for ObiH were surveyed at both room temperature and $4{ }^{\circ} \mathrm{C}$ by the sitting drop method of vapor diffusion using JCSG -plus HT96 (Molecular Dimensions) and HT index HR2-134 (Hampton Research) sparse matrix screens with 17 and $34 \mathrm{mg} / \mathrm{mL}$ of ObiH. Crystals appeared in two of the wells that were screened at room temperature containing $0.1 \mathrm{M}$ Bis-Tris $\mathrm{pH}$ 6.5, 2.0 M ammonium sulfate and 0.1 M Tris $\mathrm{pH} 8.5,2.0 \mathrm{M}$ ammonium sulfate, respectively, at both the concentrations of ObiH. After optimization, 0.1 M Bis-Tris pH 6.75 - 7.0, 1.8 - 2.0 M ammonium sulfate, $10-20 \mathrm{mg} / \mathrm{mL}$ of ObiH was 
found to be the best crystallization condition that resulted in reproducible crystal formation. Crystals grew over the course of three days and were pink in color. Crystals were stable in the dark over several months. For X-ray data collection, a cryoprotectant solution containing 30\% glycerol, $0.1 \mathrm{M}$ Bis-Tris $\mathrm{pH} 6.75-7.0$, $1.8-2.0 \mathrm{M}$ ammonium sulfate was added to crystal containing droplets and allowed to incubate for $2-30$ minutes. After $\sim 10$ minutes in the cryoprotectant solution, the crystals slowly solubilized as observed by the loss of sharp edges in the crystal. To our surprise, the crystals retained most of their core structure, and were flash frozen in liquid $\mathrm{N}_{2}$ until diffraction.

X-ray data were collected remotely at the Advanced Photon Source, Structural Biology Center Beamline 23-ID-D. The X-ray data were processed with xia2 and Aimless. We solved the structure via molecular replacement with PHASER, using the structure of Serine hydroxymethyltransferase [Protein Data Bank (PDB) ID: 4OT8] as a starting model. Unfortunately, ObiH crystals were highly twinned ( $>25 \%)$ and Xray data from multiple crystals were processed to identify the crystal with least twinning. Iterative cycles of model building with COOT and refinement with REFMAC reduced Rwork and Rfree to $21.3 \%$ and $24.2 \%$, respectively, from 50 to 1.66 - $\AA$ resolution. The crystals belonged to space group $\mathrm{P} 4_{1}$ with the following unit cell dimensions: $\mathrm{a}=118.6 \AA, \mathrm{b}=118.6 \AA, \mathrm{c}=130.0 \AA, \alpha=90^{\circ}, \beta=90^{\circ}$ and $\gamma=90^{\circ}$. The asymmetric unit contained four subunits. Relevant X-ray data collection and model refinement statistics are listed in Table S1. Crystallization with L-threonine, L-allo-threonine, L-serine, L-glycine or L-penicillamine did not result in high-quality diffraction data.

\section{Forcefield parameterization of PLP internal aldimine and L-Threonine external aldimine}

Coordinate scan calculations were performed using the Gaussian 16 revision C.01 software package ${ }^{2}$. All relaxed coordinate scans and optimizations were conducted in the gas phase using the B3LYP/6-31G* method and basis set combination with tight optimization criteria. Dihedral potential energy surfaces were fit using Python 3.6.4 ${ }^{3}$ and the SciPy 1.2.1 curve_fit module ${ }^{4}$. The following GROMACS Dihedral Type 9 
periodic energy barrier equation ${ }^{5}$ was used during fitting to extract relevant forcefield parameters (force constant $k_{\phi}$, periodicity $n$, and phase $\left.\phi_{S}\right)$ :

$$
V_{d}\left(\phi_{i j k l}\right)=k_{\phi}\left(1+\cos \left(n \phi-\phi_{s}\right)\right)
$$

For internal aldimine parameterization, a truncated model of the residue was used to parameterize the NZC4'-C4-C3 dihedral. This model lacks a phosphate group (replaced with a hydroxyl group) and backbone atoms (sidechain begins at $\mathrm{C} \beta$ as $-\mathrm{CH} 3$ ), which move during gas phase calculations and lead to significant distortion of the residue structure. The C4-C5-C5'-O5 and CD-CE-NZ-C4' dihedrals were frozen to prevent intramolecular imine-alcohol hydrogen bonding and sidechain distortions, respectively. The NZ-C4'-C4$\mathrm{C} 3$ dihedral rotation was scanned in steps of $10^{\circ}$ to generate the relevant rotational potential energy surface. Fitting of the surface to the above equation generated the following forcefield parameters: $k_{\phi}=97.45$ $\mathrm{kJ} / \mathrm{mol}, n=2, \phi_{s}=-180.00^{\circ}$. Relevant topology information for the complete residue was generated using the acepyp.py script available from AMBERTools196. This topology was merged with the Lys residue information in the AMBER99SB-ILDN forcefield ${ }^{7}$ aminoacids.rtp file and aminoacids.hdb file to produce a complete non-standard amino acid description, labeled as LLP. Relevant forcefield parameters up to $\mathrm{C} \gamma$ were used from the forcefield LYS entry, and relevant forcefield parameters from the acepyp.py generated topology files were used for the rest of the LLP residue. Charge information was merged from a ground state optimized structure of the internal aldimine model structure, starting at the lowest energy point sampled by the coordinate scan, and modified to produce an appropriate integer charge state. Full integration of these data into the forcefield enables proper processing of internal aldimine PDB structures using the GROMACS pdb2gmx module.

For L-Threonine external aldimine parameterization, a full model of the ligand was used to parameterize the C4'-N-CA-CB dihedral. The C4-C5-C5'-O5 and C5-C5'-O5-P dihedrals were frozen to prevent significant reorientation of the phosphate group, which is expected to engage in stabilizing hydrogen bonds in the ObiH active site which are absent in the gas phase calculations, leading to distortions of the LThreonine moiety during the course of the coordinate scans. The C4'-N-CA-CB dihedral was scanned in 
steps of $10^{\circ}$ to generate the relevant rotational potential energy surface. Fitting of the surface to the above equation generated the following forcefield parameters: $k_{\phi}=36.33 \mathrm{~kJ} / \mathrm{mol}, n=2, \phi_{s}=320^{\circ}$. Relevant topology information for the ligand was generated using acepype.py, as above, and the produced ITP file was modified with the fit C4'-N-CA-CB dihedral parameters and the forcefield parameters of the NZ-C4'C4-C3 dihedral rotation from the internal aldimine parameterization.

\section{Molecular Dynamics Simulations}

Simulations were performed using GROMACS 5.1. ${ }^{8}$ and the AMBER99SB-ILDN forcefield ${ }^{7}$ with TIP3P water model $^{9}$. The forcefield was modified to properly incorporate the internal aldimine of PLP as the residue LLP as described above. All time course simulations were conducted with a 2 fs timestep. The protonation state of titratable residues at $\mathrm{pH} 8.5$ was determined using the PlayMolecule ProteinPrepare webserver $^{10}$. The protonation states of Glu107 and Asp204 were fixed as deprotonated to prevent biasing of hydrogen bond sampling with the cofactor protonated pyridine nitrogen. For internal aldimine simulations, the crystal structure was first processed using the GROMACS pdb2gmx function. Crystallographic waters were maintained during the conversion process ${ }^{11}$. The simulation box was modified to place the protein in a rhombic dodecahedral box with a $1.2 \mathrm{~nm}$ distance between the solute and box edge. The box was then solvated, and solvent molecules were randomly replaced with sodium ions to neutralize the box charge. The system was the energy minimized to a tolerance of $100 \mathrm{~kJ} / \mathrm{mol}$, followed by a $30 \mathrm{ps}$ heavy atom restrained simulation to allow water reorientation to occur. Simulated annealing was done in triplicate over $1.2 \mathrm{~ns}$ to bring the simulation from $50 \mathrm{~K}$ to $310 \mathrm{~K}$ using LINCS constrain algorithm ${ }^{12}$, Particle-mesh Ewald treatment of long-range electrostatic interactions ${ }^{13}$ with a Van der Waals interaction cut-off of $1 \mathrm{~nm}, \mathrm{~V}$-rescale thermostat ${ }^{14}$, and Berendsen barostat ${ }^{15}$ (1.0 bar). The triplicate simulations were then subjected to a 10 ns NVT simulation, with the thermostat control changed to Nose-Hoover ${ }^{16,17}$ at 310 $\mathrm{K}$, for initial equilibration. Final $110 \mathrm{~ns}$ production run trajectories were then generated under NPT 
equilibration, with the barostat control changed to Parrinello-Rahman ${ }^{18}(1 \mathrm{bar})$, and the first $10 \mathrm{~ns}$ of each simulations were disregarded to avoid pre-equilibration artifacts.

For L-Threonine external aldimine simulations, the titrated structure from PlayMolecule was used as a starting point. The LLP234 residues of both chains were mutated to lysine using PyMOL 2.0.0, removing the PLP cofactor. A second PDB file containing only the external aldimine ligands was generated using a structurally similar external aldimine structure of serine hydroxymethyltransferase (SHMT) ${ }^{19}$ (PDB: 4OT8, $2.96 \AA$ backbone RMSD) by superimposing the SHMT structure onto the ObiH structure and manually aligning L-Threonine external aldimine ligand to the L-serine external aldimine ligands. The apo ObiH structure was processed using the GROMACS pdb2gmx function to generate the protein topology information, while the ligand structure was converted to the appropriate gro file format using the GROMACS editconf function. The resulting .gro files were manually merged, and the simulation topology file was modified to include the ligand topology. The remainder of the simulation process was identical to the internal aldimine simulations.

Analysis of trajectories was performed using a combination of built-in GROMACS analysis tools and Python 3.6.4 with the MDAnalysis 0.18.0 package ${ }^{20,21}$, Numpy 1.19.1 package ${ }^{22}$, and Matplotlib 2.2.2 package $^{23}$. Energy analysis of the trajectory temperatures, pressures, box volumes, and densities all indicate that the systems have achieved equilibration within the $10 \mathrm{~ns}$ initial window, which were excluded from analysis. Hydrogen bond analysis was performed with the following geometric criteria: Donor-acceptor distance $\leq 3.0 \AA$, donor-hydrogen-acceptor angle $\geq 150^{\circ}$. PLP-His131 ring distances were calculated using the centers of geometry for both rings. Phe68-Trp132 distances were calculated using the centers of geometry for both sidechains to capture potential gating dynamics. Arg366-Thr carboxylate distances were calculated between Arg-C $\zeta$ and the carboxylate carbon of the cofactor bound Thr. Free energy surfaces were generated using the weighted histogram analysis method (WHAM) ${ }^{24}$, using order parameters as indicated on the relevant plot axes. 


\section{Design of site-saturation mutagenesis library}

PCR was conducted using Phusion polymerase (New England Biolabs) according to the standard protocol. For the given site of mutagenesis, three primers were designed containing codons NDT (encoding for Ile, Asn, Ser, Gly, Asp, Val, Arg, His, Leu, Phe, Tyr, and Cys), VHG (encoding for Met, Thr, Lys, Glu, Ala, Val, Gln, Pro, and Leu), and TGG (Trp), respectively, thereby including all 20 natural amino acids. These

three primers were mixed in a ratio 12:9:1 according to the previously described protocol. ${ }^{25}$ Library plasmids were constructed by overlap extension PCR using the plasmid that contained the wt-ObiH gene in the pET28(b)+ vector as a template. DpnI was added to digest the template DNA $(1 \mu \mathrm{L}$ per $50 \mu \mathrm{L}$ PCR reaction, incubated at $37^{\circ} \mathrm{C}$ for 1 hour), and the amplified library genes were purified by preparative agarose

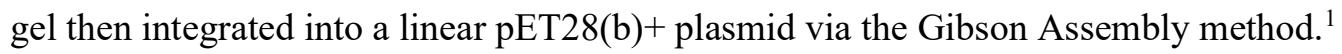

For E107Q and D204N variants, a single primer containing codons CAA and AAT at the site of mutagenesis were used, respectively. Mutant plasmids were constructed by overlap extension PCR using the plasmid that contained the wt-ObiH gene in the pET28(b)+ vector as a template. The resulting amplified mutant genes were purified and integrated as above.

\section{Library expression and screening}

BL21 (DE3) E. coli cells carrying parent and variant plasmids were grown in 96-deep-well plates (600 $\mu \mathrm{L} /$ well TB-Kan) at $37{ }^{\circ} \mathrm{C}$ with shaking at $200 \mathrm{rpm}$. After shaking at $250 \mathrm{rpm}$ overnight, $10 \mu \mathrm{L}$ of the overnight cultures were transferred to new deep-well plates containing $600 \mu \mathrm{L} /$ well TB-Kan, which were allowed to grow at $37^{\circ} \mathrm{C}$ with shaking at $200 \mathrm{rpm}$. After $3 \mathrm{~h}$, the plates were chilled on ice for $30 \mathrm{~min}$, then induced by the addition of IPTG in TB-Kan (1 mM final concentration). The cultures were expressed for 16 hours at $20^{\circ} \mathrm{C}$ with shaking. After 20 hours, cells were harvested by centrifugation at $4,300 \times \mathrm{g}$ for 20 min. The cell pellets were frozen at $-20^{\circ} \mathrm{C}$ for a minimum of 2 hours. For screening, cells were thawed at room temperature and then lysed by the addition of $250 \mu \mathrm{L}$ of lysis buffer ( $50 \mathrm{mM}$ potassium phosphate 
buffer buffer $\mathrm{pH}$ 8.0, $500 \mathrm{mM} \mathrm{NaCl}, 1 \mathrm{mg} / \mathrm{ml}$ Hen Egg White Lysozyme (GoldBio), $0.2 \mathrm{mg} / \mathrm{ml}$ DNaseI (GoldBio), $1 \mathrm{mM} \mathrm{MgCl2}, 1 \mathrm{X}$ BugBuster Protein extraction reagent (Novagen) and $400 \mu \mathrm{M}$ PLP). The plates were incubated for $1 \mathrm{~h}$ at $37^{\circ} \mathrm{C}$. The resulting lysate was spun down at 4,300×g for 20 min to pellet cell debris and supernatants were transferred to a new 96-well deep-well plate.

$15 \mathrm{mM}$ of Biphenyl-4-carboxaldehyde (from a $500 \mathrm{mM}$ stock solution in DMSO) and $75 \mathrm{mM}$ of Thr (from a $500 \mathrm{mM}$ stock solution in water) were added to each well, followed by $50 \mathrm{mM}$ potassium phosphate, $\mathrm{pH}$ 8.0 buffer such that the total volume in the wells was $250 \mu \mathrm{L}$. The plates were sealed with Teflon sealing mats, then incubated at $37{ }^{\circ} \mathrm{C}$ for 6 hours. After 6 hours, the reactions were quenched with $250 \mu \mathrm{L}$ of acetonitrile. Quenched reaction mixtures were filtered using a filter plate to remove debris (by centrifugation at $4,300 \times \mathrm{g}$ for $5 \mathrm{~min}$ ) prior to UPLC-MS injection. Relative activity and diastereomeric ratio were calculated by comparing the product $\mathrm{UV}$-vis absorbance peak areas at $254 \mathrm{~nm}\left(\mathrm{~A}_{254}\right)$ to the $\mathrm{A}_{254}$ absorbance from the wt-ObiH wells. 


\section{Supplemental Figures}

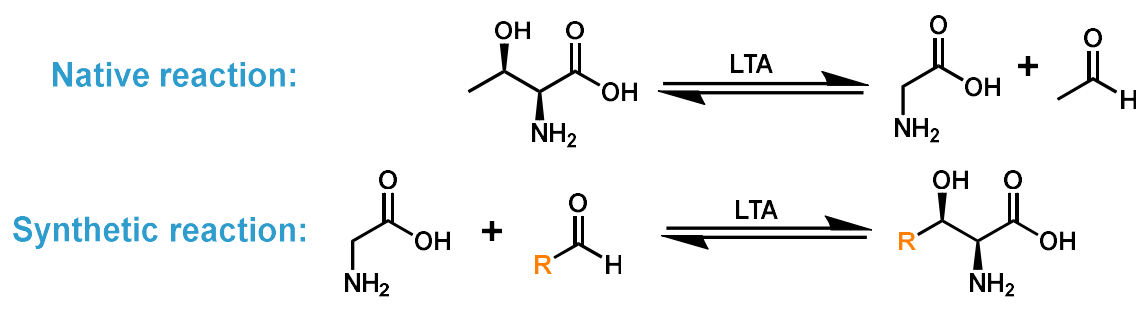

Figure S1. Native and synthetic LTA reactions. LTA catalyzes the breakdown of Thr into glycine and acetaldehyde in vivo. This reaction can be reversed by addition of excess glycine and aldehyde to form diverse $\beta$-hydroxy amino acids.

a

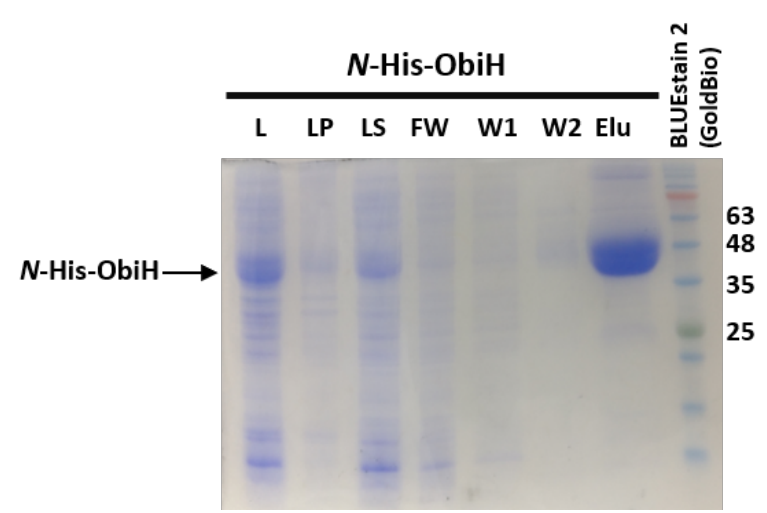

b

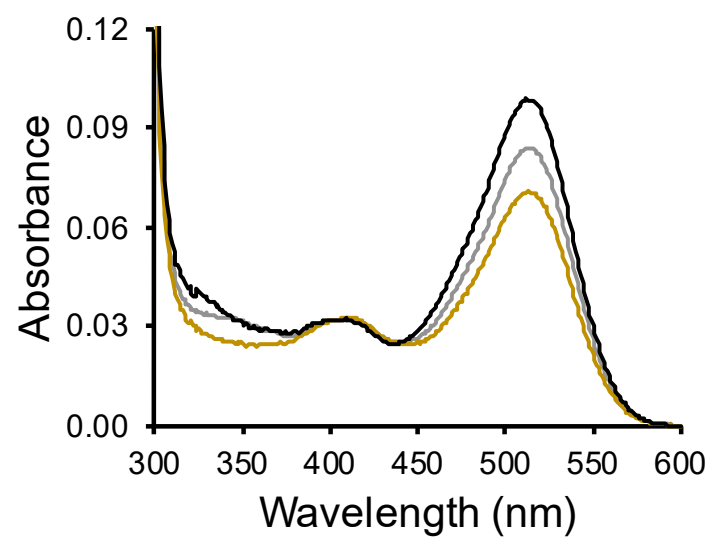

Figure S2. ObiH Purification. a) Representative SDS-PAGE from Ni-NTA purification of ObiH. L is lysate, LP is lysate pellet, LS is lysate supernatant, FW is Flow through, W1 and W2 are washes with 20 and $40 \mathrm{mM}$ Imidazole respectively, Elu is elution. The ladder used was GoldBio BLUEstain2 protein ladder. b) UV-vis spectra of as-isolated ObiH from three different preps following identical protocol. Variable amount of $515 \mathrm{~nm}$ species was observed between preps. 

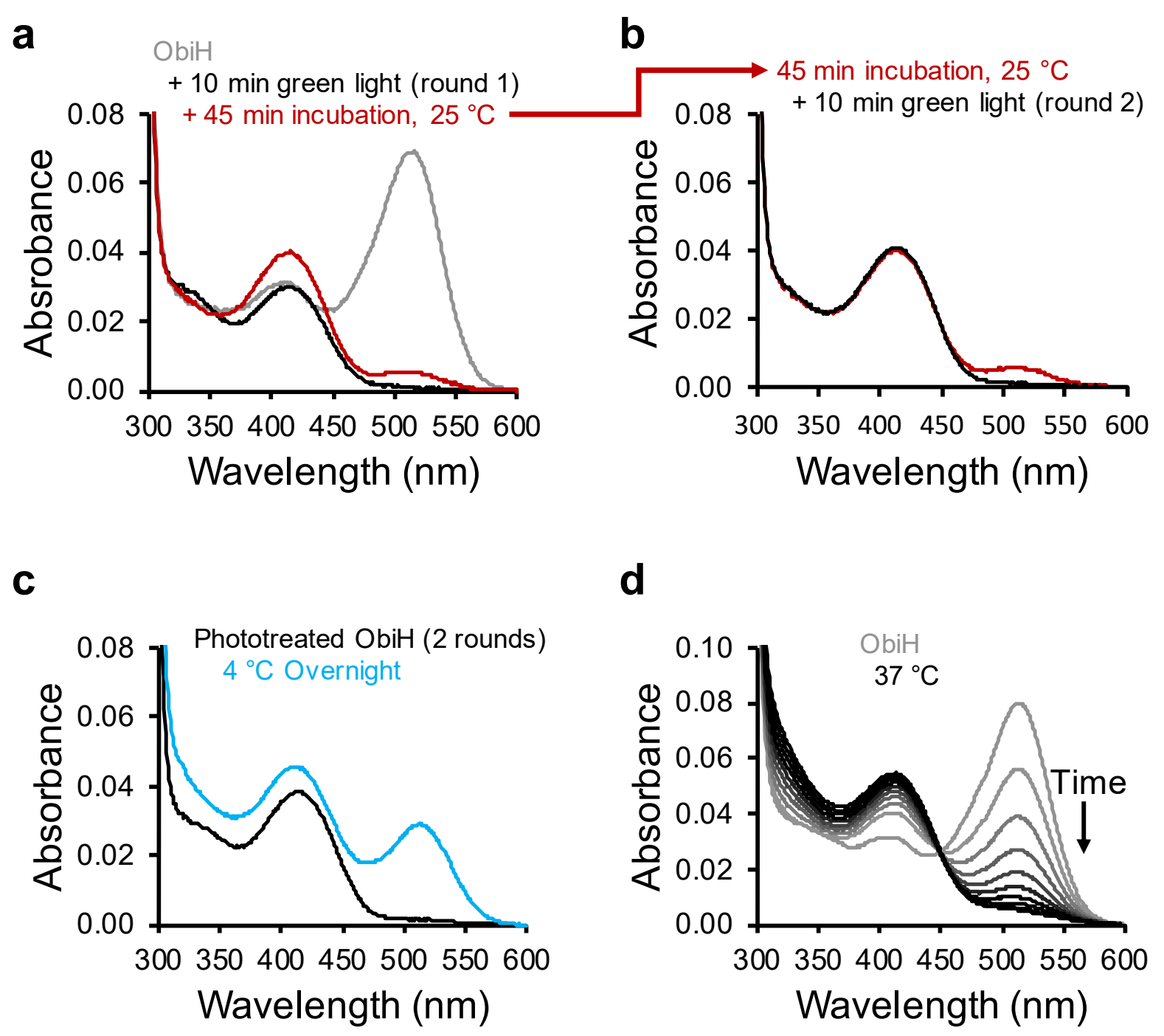

Figure S3. Phototreatment produces homogeneous ObiH. a) $1^{\text {st }}$ round of phototreatment. $20 \mu \mathrm{M}$ asisolated ObiH (gray). Phototreatment with green light for 10 min results in complete ablation of $515 \mathrm{~nm}$ peak (black) and an increase at $340 \mathrm{~nm}$. After $45 \mathrm{~min}$ (dark red), the $340 \mathrm{~nm}$ peak decreased as the 415 $\mathrm{nm}$ peak and the $515 \mathrm{~nm}$ increased. b) $\mathbf{2}^{\text {nd }}$ round of phototreatment. ObiH that had small peak at 515 $\mathrm{nm}$ (dark red) was photo-treated with green light for a second time to remove residual $515 \mathrm{~nm}$ species. Spectra $10 \mathrm{~min}$ after the second round of photo-treatment showed no residual $515 \mathrm{~nm}$ peak (black). c) Overnight incubation of phototreated $\mathrm{ObiH}$ resulted in the regeneration of the $515 \mathrm{~nm}$ species. Phototreated ObiH (black), and phototreated ObiH after overnight storage at $4{ }^{\circ} \mathrm{C}$ (blue). d) Incubation of $\mathrm{ObiH}$ at $37^{\circ} \mathrm{C}$ promotes the conversion of the $515 \mathrm{~nm}$ species. ObiH was incubated in UV-Vis spectrophotometer at $37^{\circ} \mathrm{C}$. Maximum $515 \mathrm{~nm}$ is observed at the start of the experiment. Subsequent spectra were gathered every $20 \mathrm{~min}$ for $3 \mathrm{~h}$. 

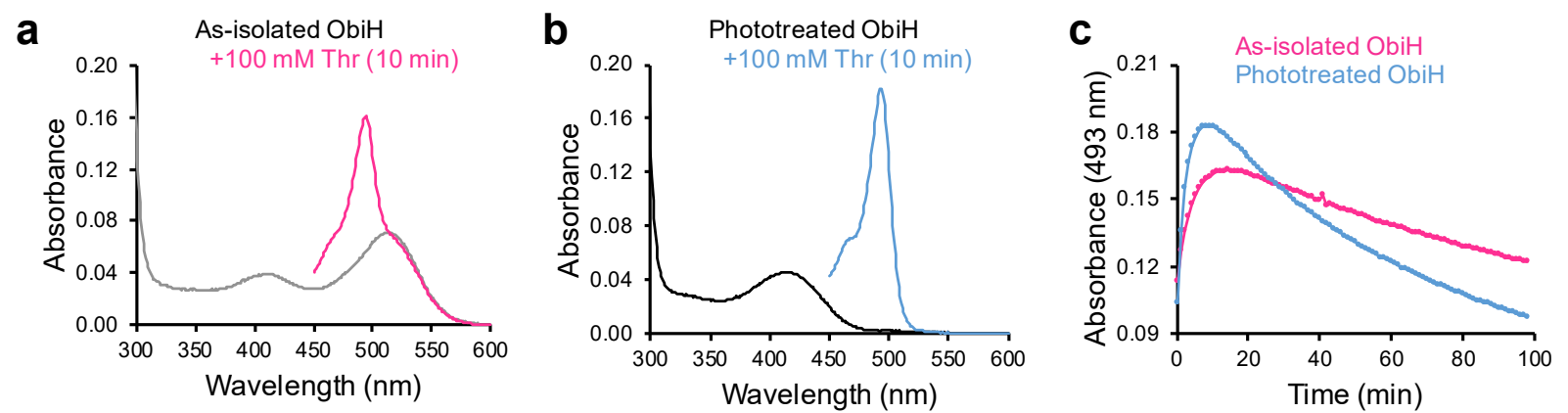

Figure S4. Phototreatment of $\mathrm{ObiH}$ produces a larger population of $\mathbf{E}\left(\mathbf{Q}^{\mathrm{Gly}}\right)$. a) Spectra of as-isolated ObiH (gray) and $10 \mathrm{~min}$ after the addition of $100 \mathrm{mM}$ Thr (pink) b) Spectra of phototreated ObiH (black) and $10 \mathrm{~min}$ after the addition of $100 \mathrm{mM} \mathrm{Thr} \mathrm{(blue).} \mathrm{c)} \mathrm{Absorbance} \mathrm{at} 493 \mathrm{~nm}$ over time for phototreated (blue) and as isolated ObiH (pink). Addition of $100 \mathrm{mM}$ Thr results in larger peak at $493 \mathrm{~nm}$ for phototreated (blue) than as isolated $\mathrm{ObiH}$ (pink). Spectra were gathered every minute from 450-600 nm.
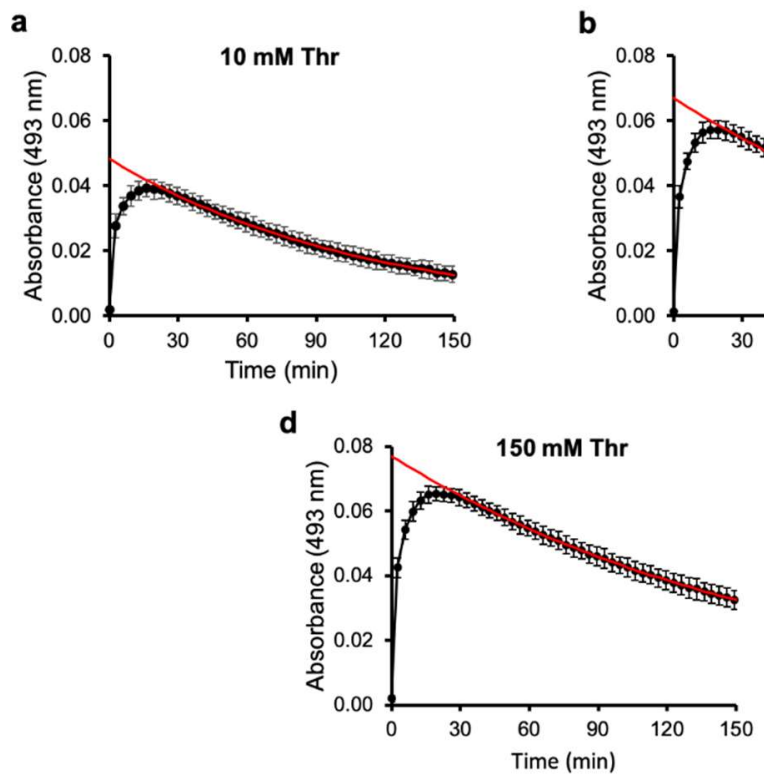

b

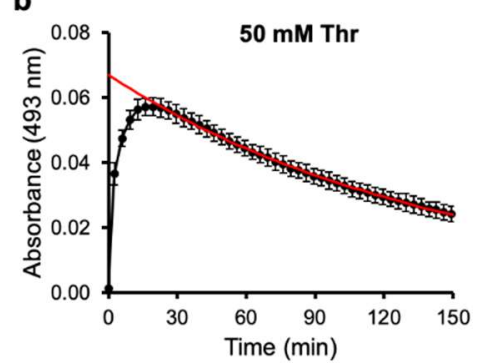

c

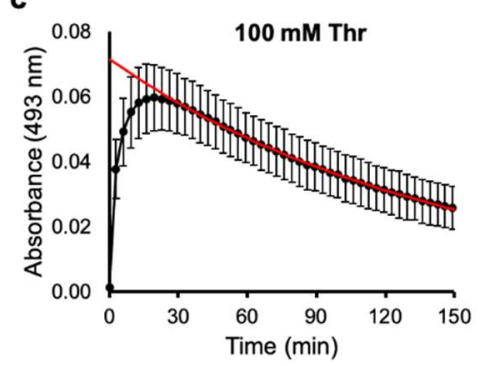

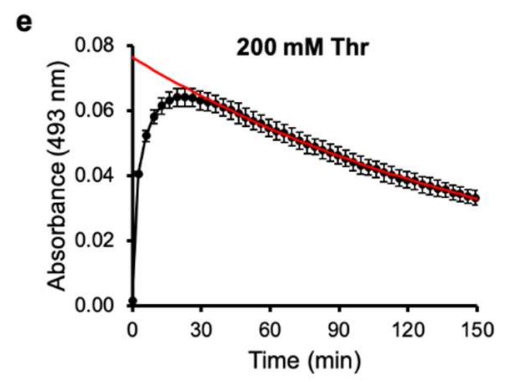

Figure S5. $\mathbf{E}\left(\mathbf{Q}^{\mathrm{Gly}}\right)$ population is dependent on concentration of Thr. Absorbance at $493 \mathrm{~nm}$ over time after the addition of $10 \mathrm{mM}$ Thr (a), $50 \mathrm{mM}$ Thr (b), $100 \mathrm{mM}$ Thr (c), $150 \mathrm{mM}$ Thr (d), and $200 \mathrm{mM}$ Thr (e) to $20 \mu \mathrm{M} \mathrm{ObiH}$. Experiments were performed in triplicate. $1^{\text {st }}$ order decay was fit to the data from 33-150 min. 

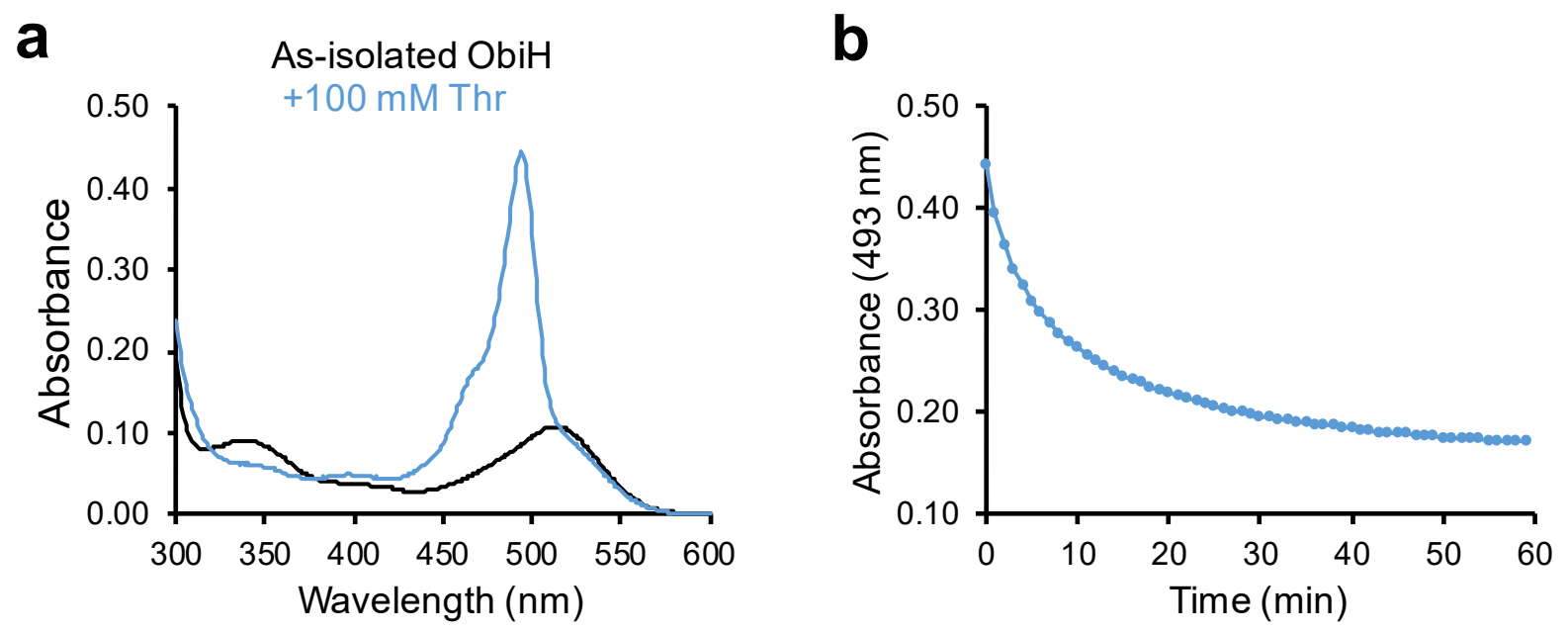

Figure S6. E( $\left(\mathbf{Q}^{\text {Gly }}\right)$ behavior at $\mathbf{p H}$ 7.0. a) $\mathrm{ObiH}$ was diluted to $20 \mu \mathrm{M}$ into $100 \mathrm{mM}$ Tris-HCl, $\mathrm{pH} 7.0$ (black). Addition of $100 \mathrm{mM}$ Thr resulted in a large peak at $493 \mathrm{~nm}$ (blue). b) absorbance at $493 \mathrm{~nm}$ over time reveals maximum quinonoid upon mixing and subsequent decay with over minutes. 

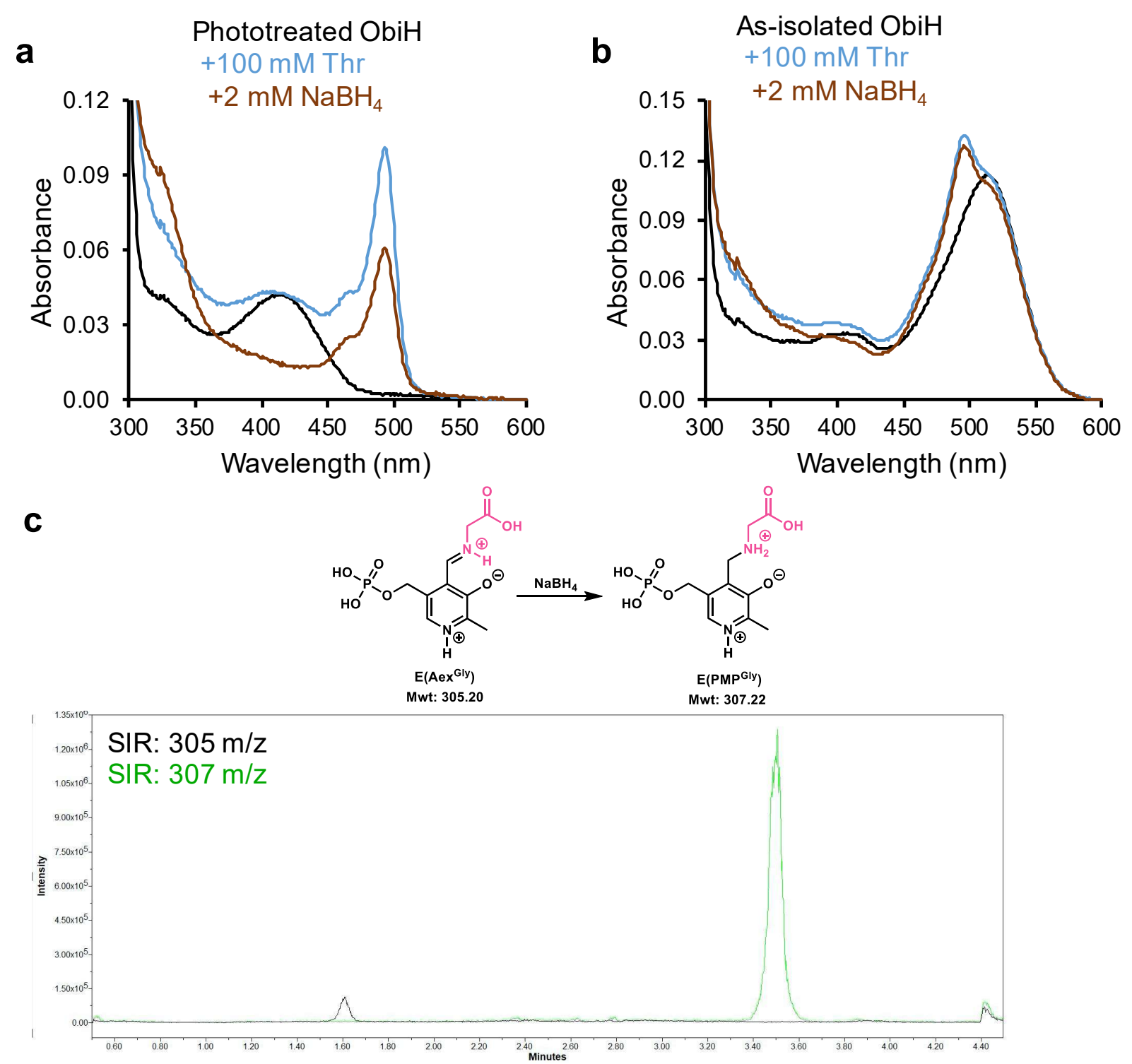

Figure $\mathrm{S7}$. $\mathrm{E}\left(\mathrm{Q}^{\mathrm{Gly}}\right)$ and $\mathrm{E}\left(\mathrm{Q}^{\text {in }}\right)$ are resistant to $\mathrm{NaBH}_{4}$ reduction. Spectrum of phototreated ObiH (black). $100 \mathrm{mM}$ Thr was added and $\mathrm{E}\left(\mathrm{Q}^{\mathrm{Gly}}\right)$ peak increased to a maximum at $10 \mathrm{~min}$ (blue). $2 \mathrm{mM}$ $\mathrm{NaBH}_{4}$ was then added and spectra were gathered every minute for $30 \mathrm{~min}$. Spectrum of reaction $25 \mathrm{~min}$ after the addition of $\mathrm{NaBH}_{4}$ (brown) shows at increase at $340 \mathrm{~nm}$ and a decrease at $415 \mathrm{~nm}$, as well as a large population of $\mathrm{E}\left(\mathrm{Q}^{\mathrm{Gly}}\right)$. b) Spectrum of $20 \mu \mathrm{M}$ as-isolated ObiH (black). $100 \mathrm{mM}$ Thr was added and $\mathrm{E}\left(\mathrm{Q}^{\mathrm{Gly}}\right)$ peak increased to a maximum at $10 \mathrm{~min}$ (blue). $2 \mathrm{mM} \mathrm{NaBH}_{4}$ was then added to the reaction and spectra were gathered every minute for $30 \mathrm{~min}$. Spectrum of reaction $25 \mathrm{~min}$ after the addition of $\mathrm{NaBH}_{4}$ (brown) shows the the $515 \mathrm{~nm}$ species was unchanged in the presence of $\mathrm{NaBH}_{4}$. c) Overlap of Single Ion Recording (SIR) measurements corresponding to $\mathrm{E}\left(\mathrm{Aex}^{\mathrm{Gly}}\right)$ and $\mathrm{E}\left(\mathrm{PMP}{ }^{\mathrm{Gly}}\right)$ after reduction of ObiH. Chemdraw figure corresponding to this transformation is shown on the top. 


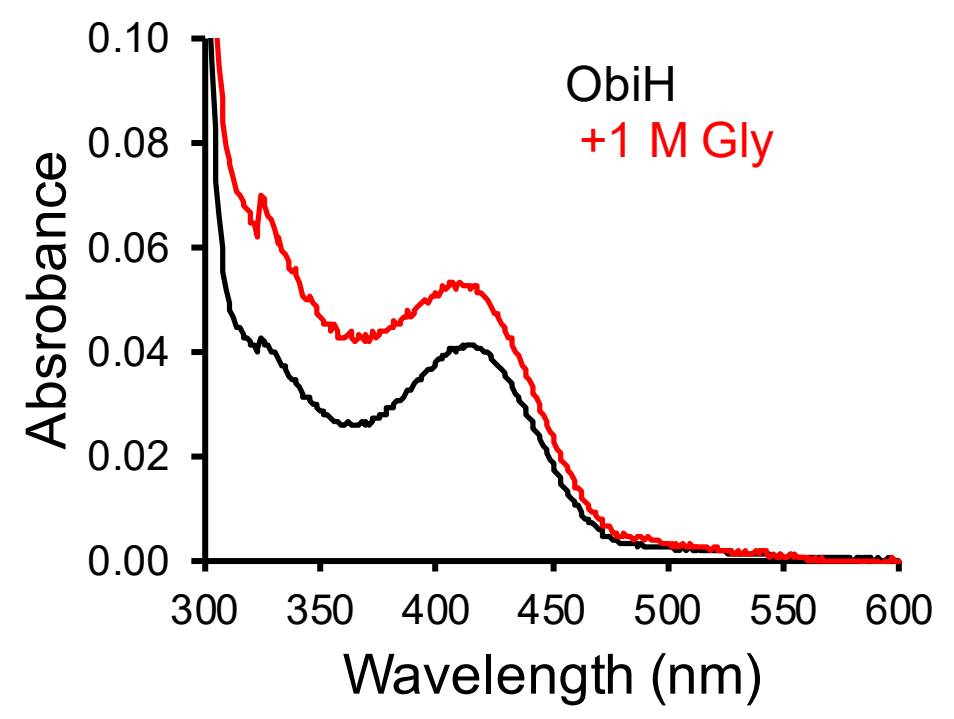

Figure S8. ObiH does not catalyze the retroaldol cleavage of Gly to form $\mathbf{E}\left(\mathbf{Q}^{\mathrm{Gly}}\right)$. Spectrum of $20 \mu \mathrm{M}$ phototreated ObiH (black). $1 \mathrm{M}$ Gly was added and spectra were acquired every 1 minute for 15 minutes. 10 min after addition of $1 \mathrm{M}$ Gly (red) shows no evidence of a peak at $493 \mathrm{~nm}$.

a

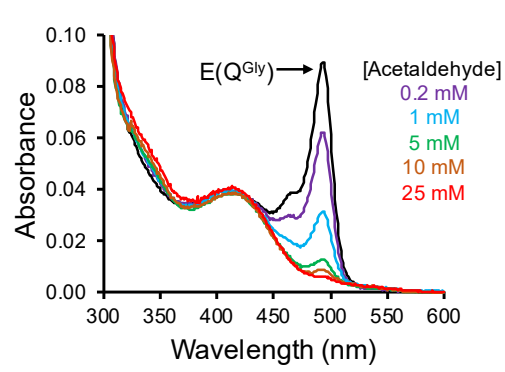

b

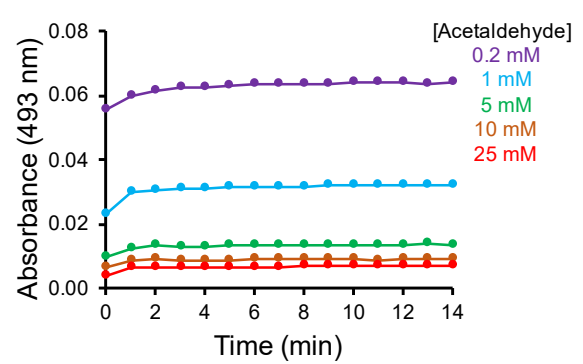

C

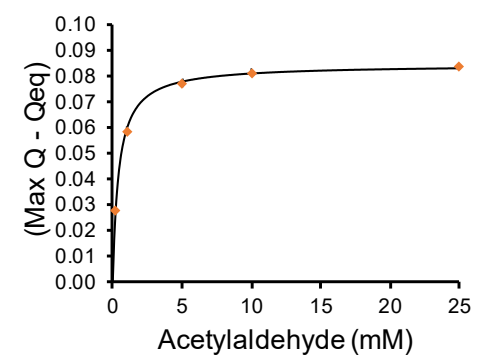

Figure $\mathbf{S 9}$. $\mathbf{E}\left(\mathbf{Q}^{\mathrm{Gly}}\right)$ rapidly reacts with acetaldehyde before reaching equilibrium. a) representative spectrum (Spectra represents average of 5 experiments containing $20 \mu \mathrm{M} \mathrm{ObiH}+100 \mathrm{mM}$ Thr prior to the addition of acetaldehyde) of phototreated ObiH 5 minutes after the addition of Thr (black). Addition of $0.2 \mathrm{mM}$ (purple), $1 \mathrm{mM}$ (blue), $5 \mathrm{mM}$ (green), $10 \mathrm{mM}$ (brown), and $25 \mathrm{mM}$ (red) acetaldehyde results in loss of the 493 peak. Spectra represent reaction 3 minutes after the addition of acetaldehyde. b) Absorbance over time at $493 \mathrm{~nm}$ after addition of $+0.2 \mathrm{mM}$ (purple), $1 \mathrm{mM}$ (blue), $5 \mathrm{mM}$ (green), $10 \mathrm{mM}$ (brown), and $25 \mathrm{mM}$ (red) acetaldehyde. c) $K_{\mathrm{D}}$ of acetaldehyde for $\mathrm{E}\left(\mathrm{Q}^{\mathrm{Gly}}\right)$ was calculating by plotting the average maximum quinonoid minus the quinonoid population at equilibrium as a function of acetaldehyde concentration. $K_{\mathrm{D}}$ was calculated to be $430 \pm 15 \mu \mathrm{M}$. 

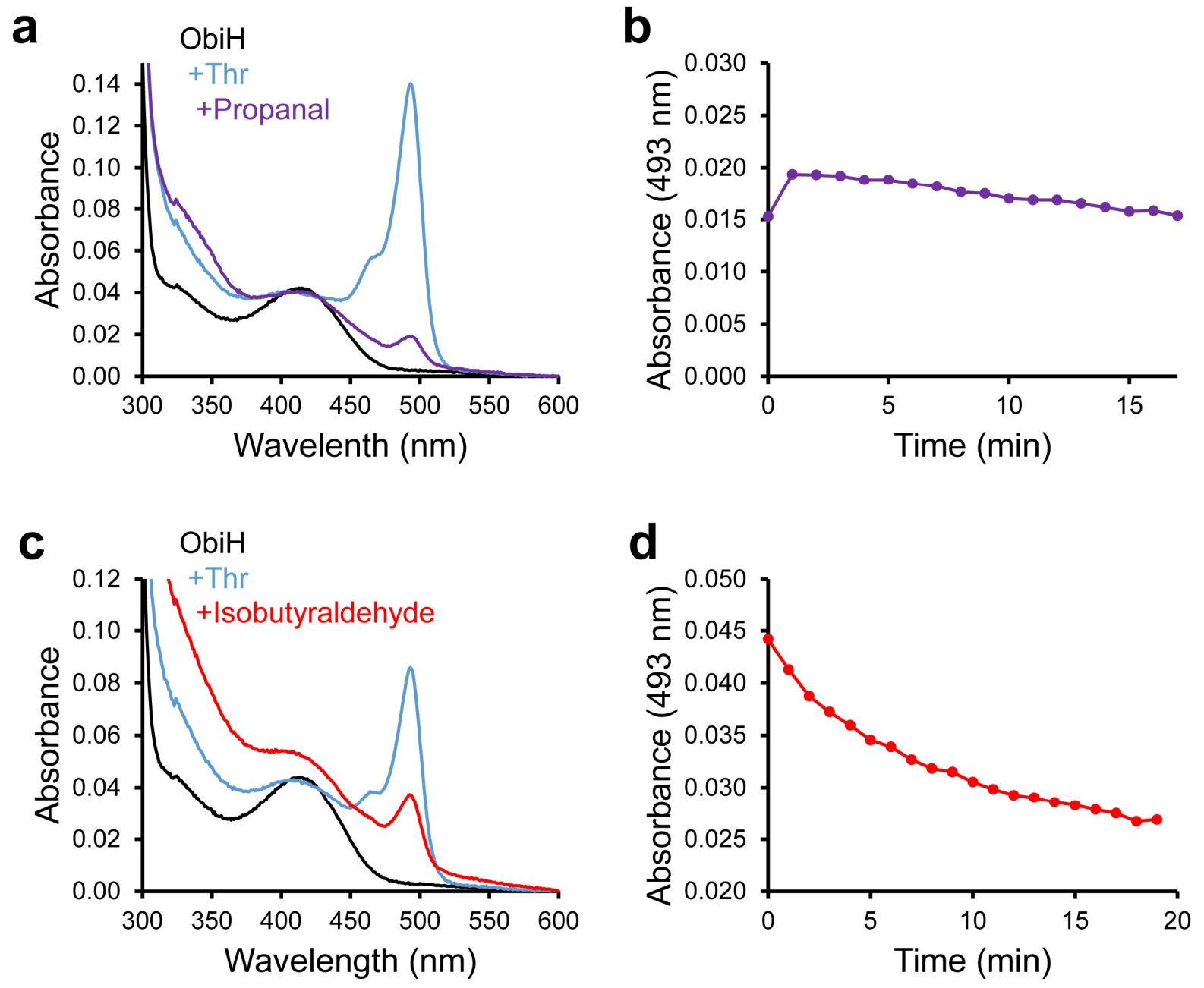

Figure S10. E( $\left(Q^{\text {Gly }}\right)$ reacts with aliphatic aldehydes. a) Spectra of phototreated ObiH (black) and ObiH + Thr 10 minutes after addition of Thr (blue). Addition of $25 \mathrm{mM}$ propanal results in substantial reduction of $\mathrm{E}\left(\mathrm{Q}^{\mathrm{Gly}}\right)$ population (purple). Spectrum represents reaction 3 minutes after the addition of aldehyde. b) Absorbance at $493 \mathrm{~nm}$ over time after the addition of propanal. c) Spectra of phototreated ObiH (black) and $\mathrm{ObiH}+\mathrm{Thr} 10$ minutes after addition of Thr (blue). Addition of $25 \mathrm{mM}$ isobutyraldehyde results in reduction of $\mathrm{E}\left(\mathrm{Q}^{\mathrm{Gly}}\right)$ population (red). Spectrum represents reaction 3 minutes after the addition of aldehyde. d) Absorbance at $493 \mathrm{~nm}$ over time after the addition of isobutyraldehyde. 
a

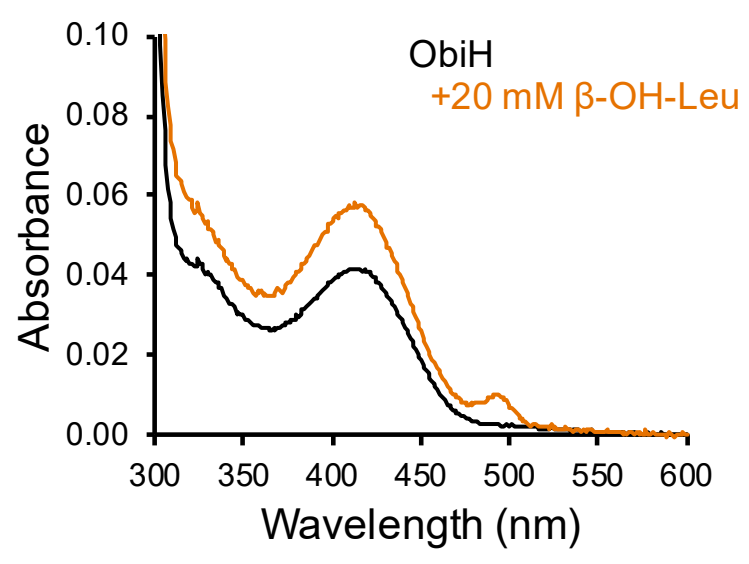

b

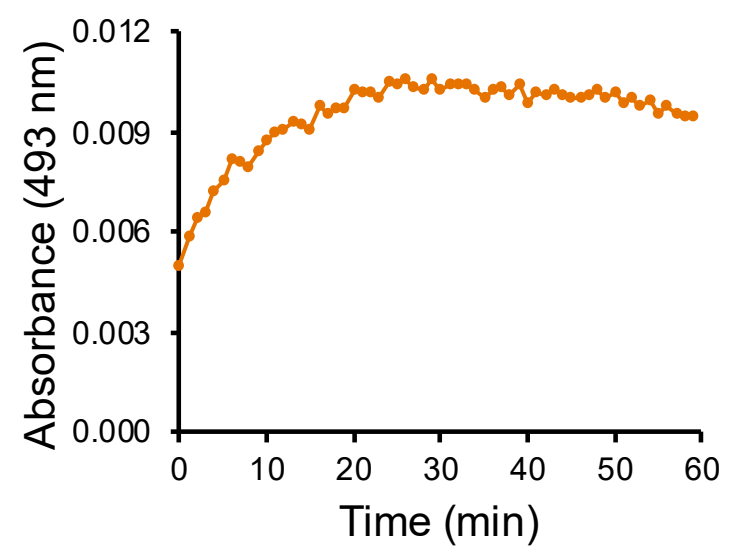

Figure S11. A small population of $\mathbf{E}\left(Q^{\mathrm{Gly}}\right)$ is formed upon addition of $\boldsymbol{\beta}$-OH-Leu. a) Spectrum of phototreated ObiH (black). Addition of $20 \mathrm{mM} \beta-\mathrm{OH}-\mathrm{Leu}$ (orange) produces a small population of $\mathrm{E}\left(\mathrm{Q}^{\mathrm{Gly}}\right)$ at $493 \mathrm{~nm}$. b) Absorbance at $493 \mathrm{~nm}$ over time.

a

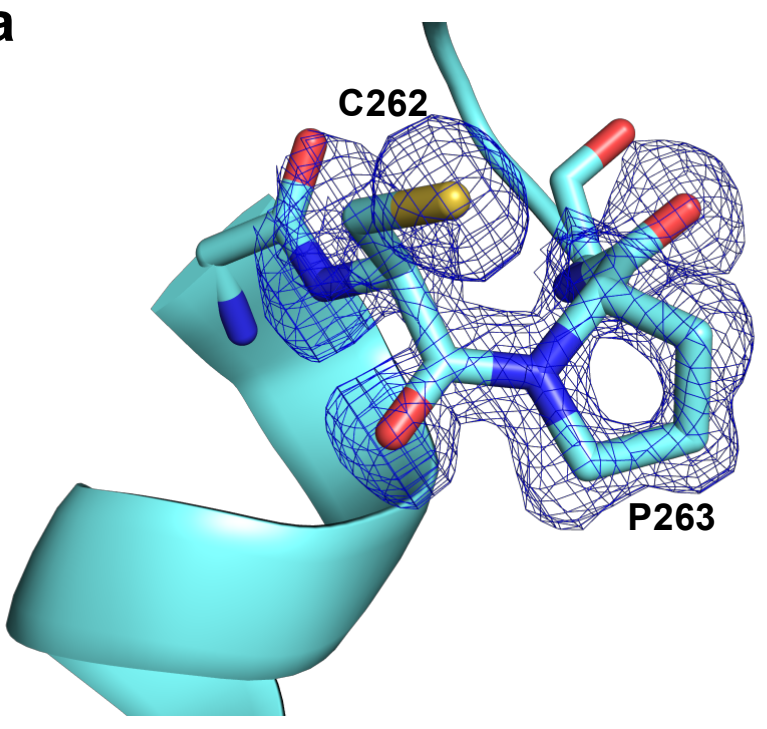

b

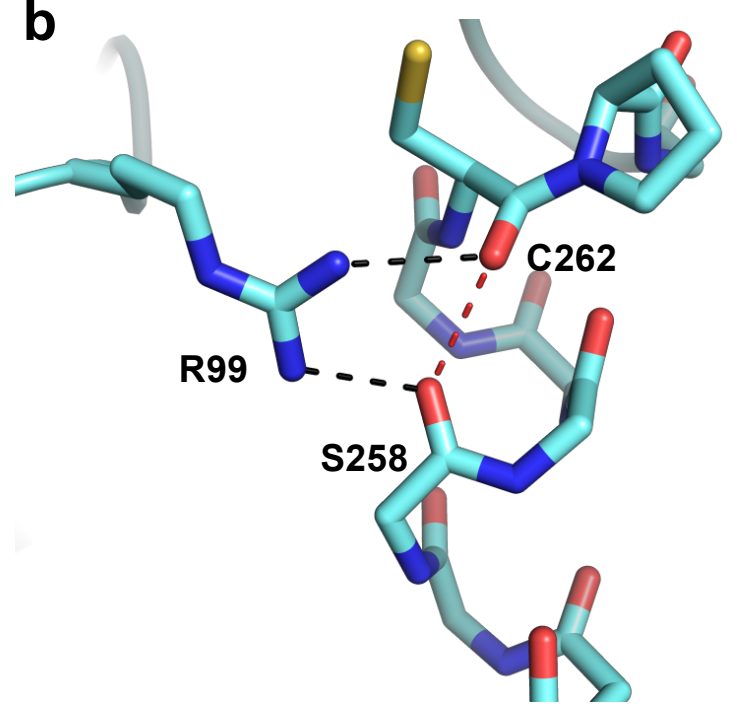

Figure S12. Uncommon structural features of ObiH. a) Cys-cisPro linkage (shown as sticks) in a $\pi$ buldge of an a-helix superimposed on the $2 M F o-D F c$ electron density map (blue mesh, $\sigma=1.5$ ). b) Strained conformation due to the destabilizing interaction between carbonyl oxygens of C262 and S258 due to the $\pi$-buldge appears to be stabilized by the H-bonds from each carbonyls to Arg99. Hydrogen bonds are shown as black dashes. Destabilizing interaction is shown as red dashes. 
a

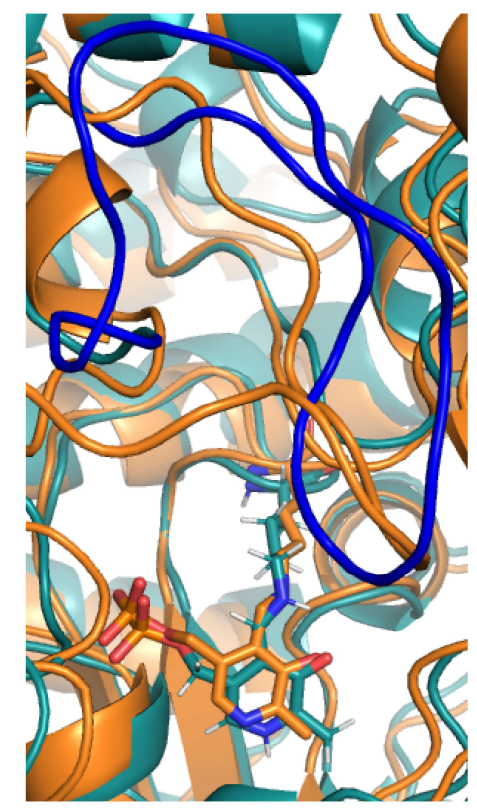

b

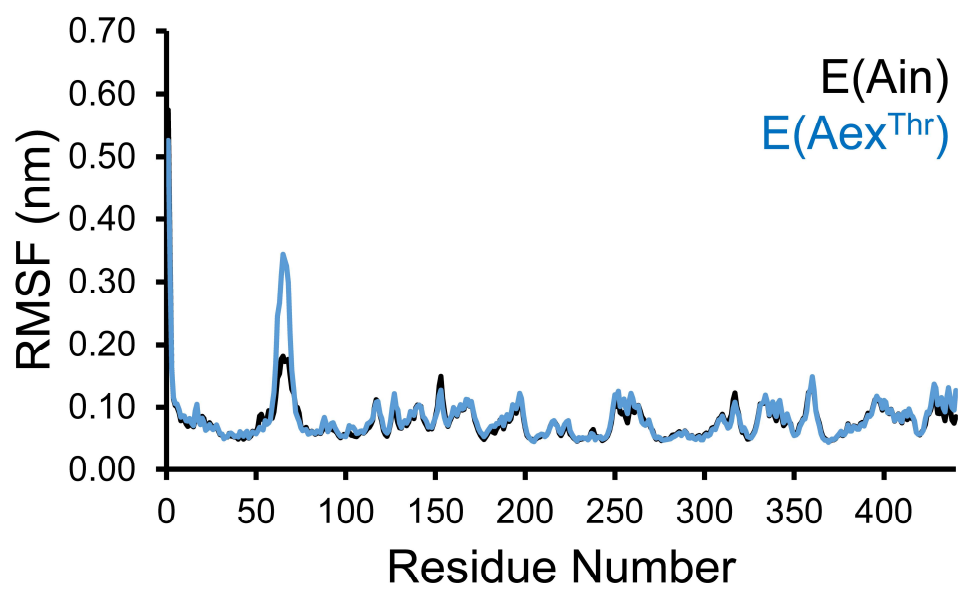

C

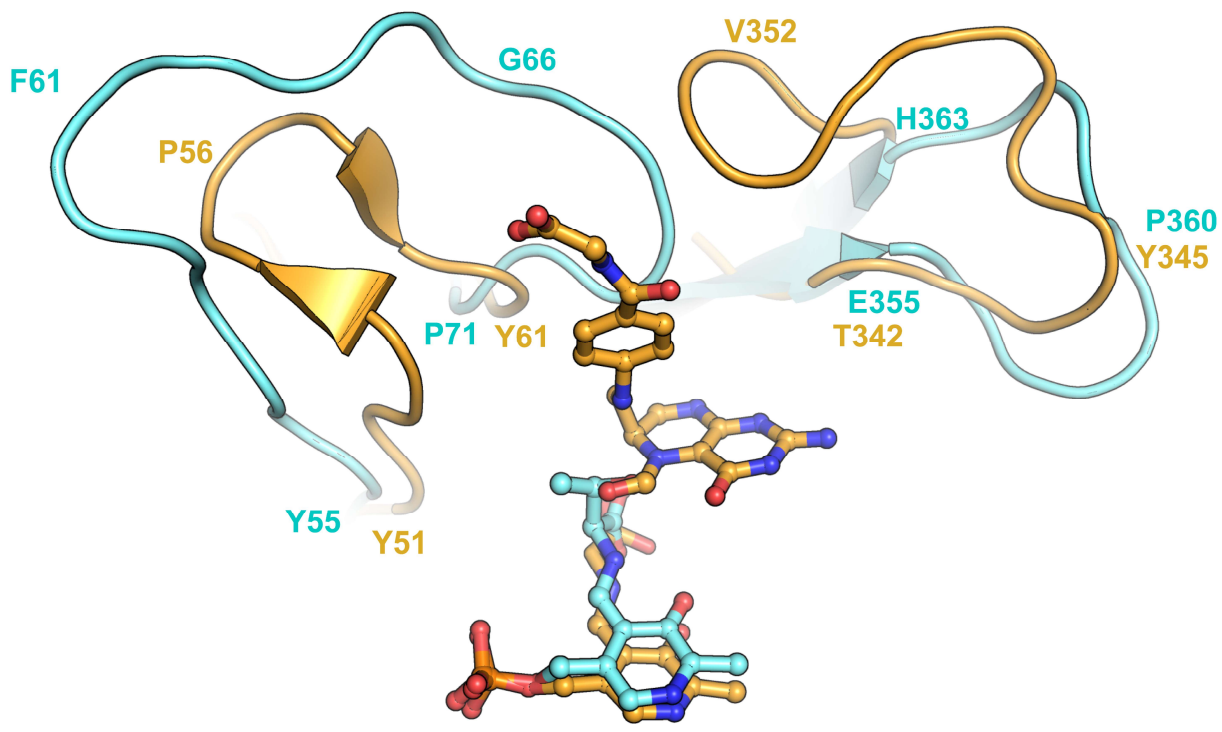

Figure S13. Conformational dynamics analysis of MD simulations. a) Superimposed view of the substrate access channel in the E(Ain) post-annealing structure (aqua) and crystal structure (orange). An identified highly mobile loop region is shown in dark blue. b) Backbone per-residue RMSF analysis of $\mathrm{E}$ (Ain) (black) and $\mathrm{E}\left(\mathrm{Aex}^{\mathrm{Thr}}\right)$ (blue). c) Superimposed view of the substrate access channel in the MD simulated ObiH-E(Aex ${ }^{\text {Thr }}$ ) (cyan) and SHMT-E(Aex) crystal structure (PDB ID: 1KL2) (gold). 
a

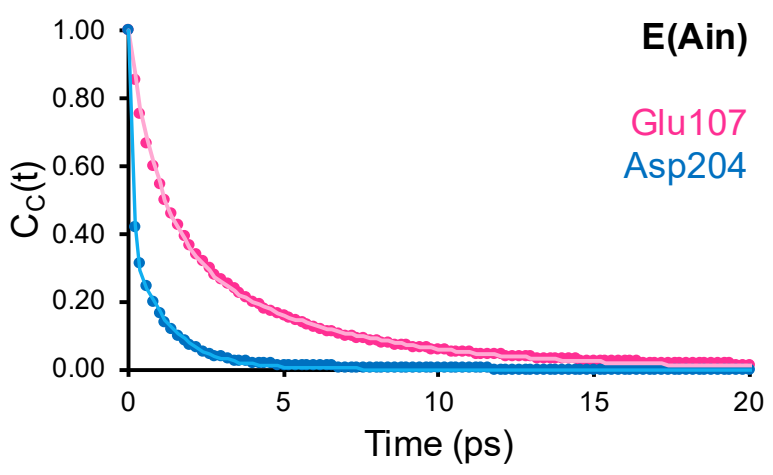

b

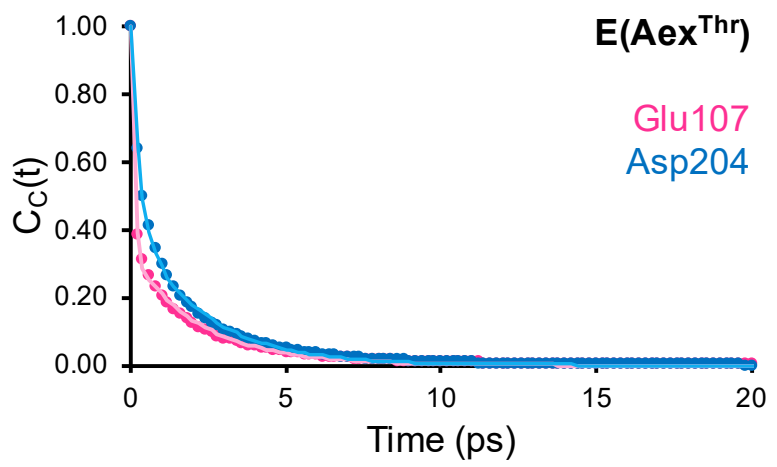

Figure S14. Average continuous autocorrelation function for PLP-N1 H-bond acceptors. Data was averaged across three replicate simulations and both monomeric subunits for the (a) E(Ain) and (b) $\mathrm{E}\left(\mathrm{Aex}^{\mathrm{Thr}}\right)$ simulation sets. Hydrogen bonding parameters to PLP-N1 of Glu107 (pink) and Asp204 (blue) were acquired by fitting to a biexponential function (light pink and light blue, respectively.)
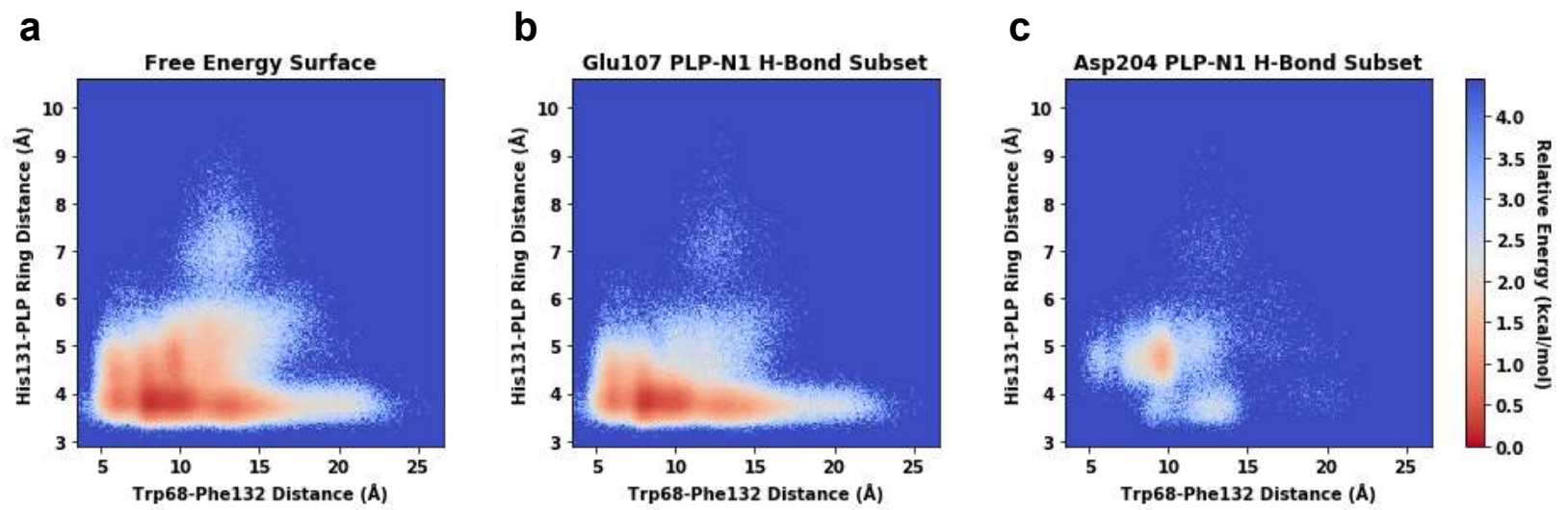

Figure S15. Free energy surface analysis of E(Ain). a) Sampled free energy surface across triplicate simulations and both E(Ain) monomers. b) Energy surface sampled when Glu107 is H-bonded to PLPN1. c) Energy surface sampled when Asp204 is H-bonded to PLP-N1. 
a

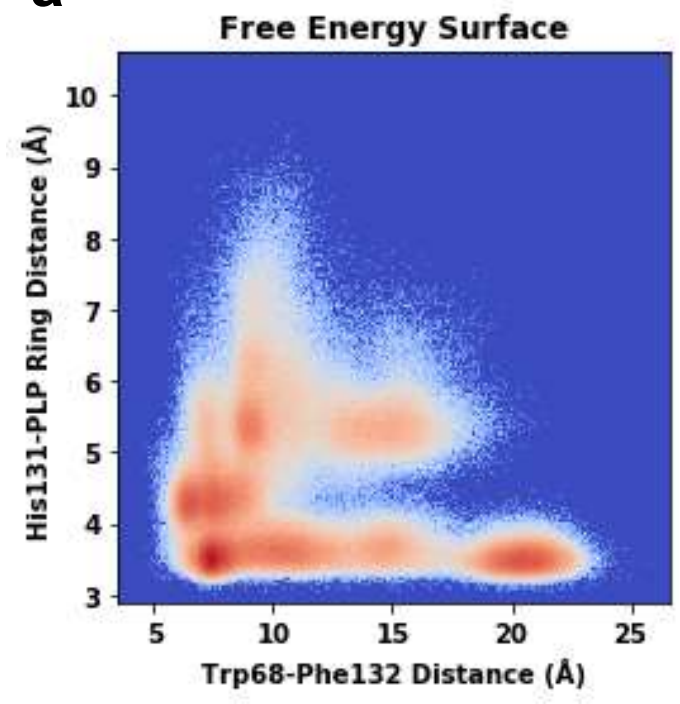

C

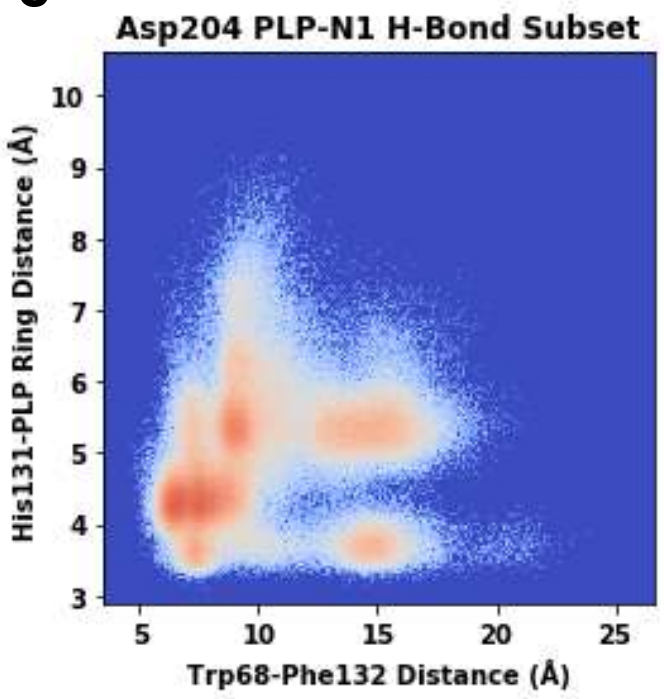

b

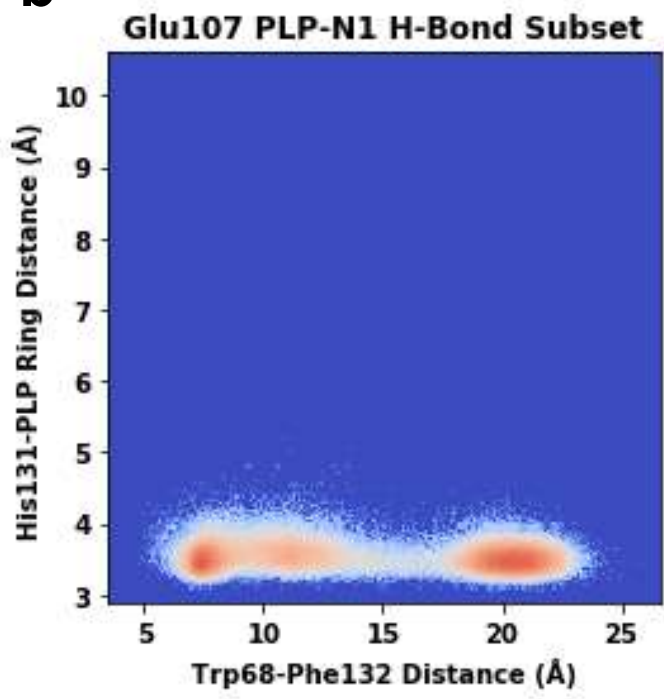

d

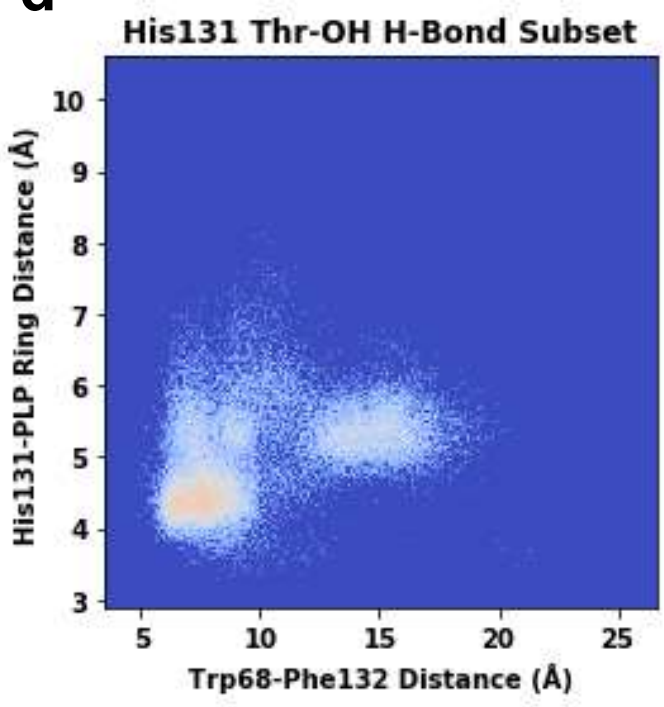

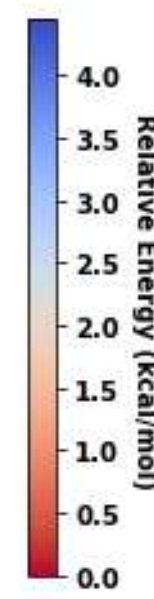

0.0

Figure S16. Free energy surface analysis of $\mathbf{E}\left(\mathbf{A e x}^{\mathrm{Thr}}\right)$. a) Sampled free energy surface across triplicate simulations and both $\mathrm{E}\left(\mathrm{Aex}^{\mathrm{Thr}}\right)$ monomers. b) Energy surface sampled when Glu107 is H-bonded to PLPN1. c) Energy surface sampled when Asp204 is H-bonded to PLP-N1. d) Energy surface sampled when His 131 is H-bonded to the hydroxyl side chain of the covalently bound Thr substrate. 
a

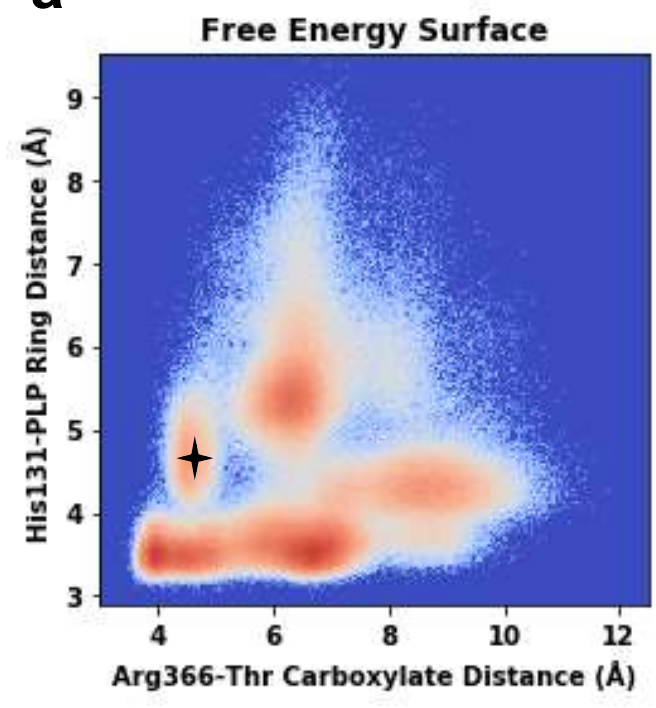

C

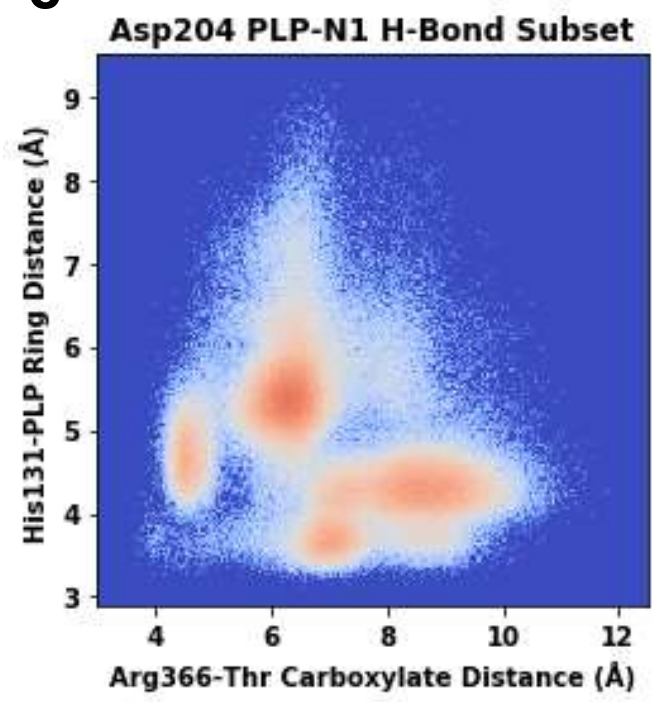

b
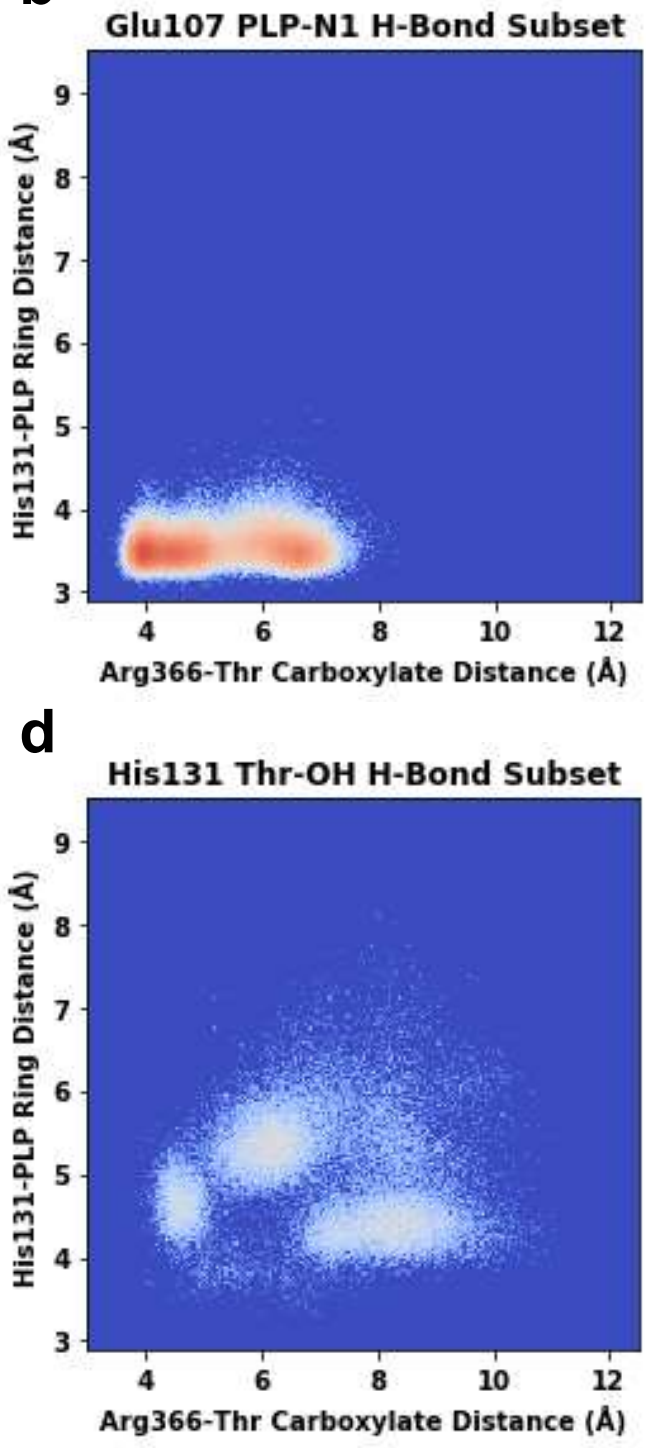

4.0

$3.5 \stackrel{\text { ग }}{\circ}$

$3.0 \stackrel{2}{\stackrel{2}{2}}$

2.5

2.0 药

1.5 증

1.0 을

0.5

0.0

Figure S17. Active site oriented free energy surface analysis of $\mathbf{E}\left(\mathrm{Aex}^{\mathrm{Thr}}\right)$. a) Sampled free energy surface across triplicate simulations and both $\mathrm{E}\left(\mathrm{Aex}^{\mathrm{Thr}}\right)$ monomers. Axes parameters were chosen to accentuate active site dynamics. The black star indicates the region from which Figure $5 \mathrm{~b}$ was derived. b) Energy surface sampled when Glu107 is H-bonded to PLP-N1. c) Energy surface sampled when Asp204 is H-bonded to PLP-N1, showing a low degree of overlap with regions accessed during Glu107 Hbonding. d) Energy surface sampled when His131 is H-bonded to the hydroxyl side chain of the covalently bound Thr substrate. These regions are almost orthogonal to regions populated during Glu107 H-bonding, instead overlapping very well with regions populated during Asp204 binding. 
a

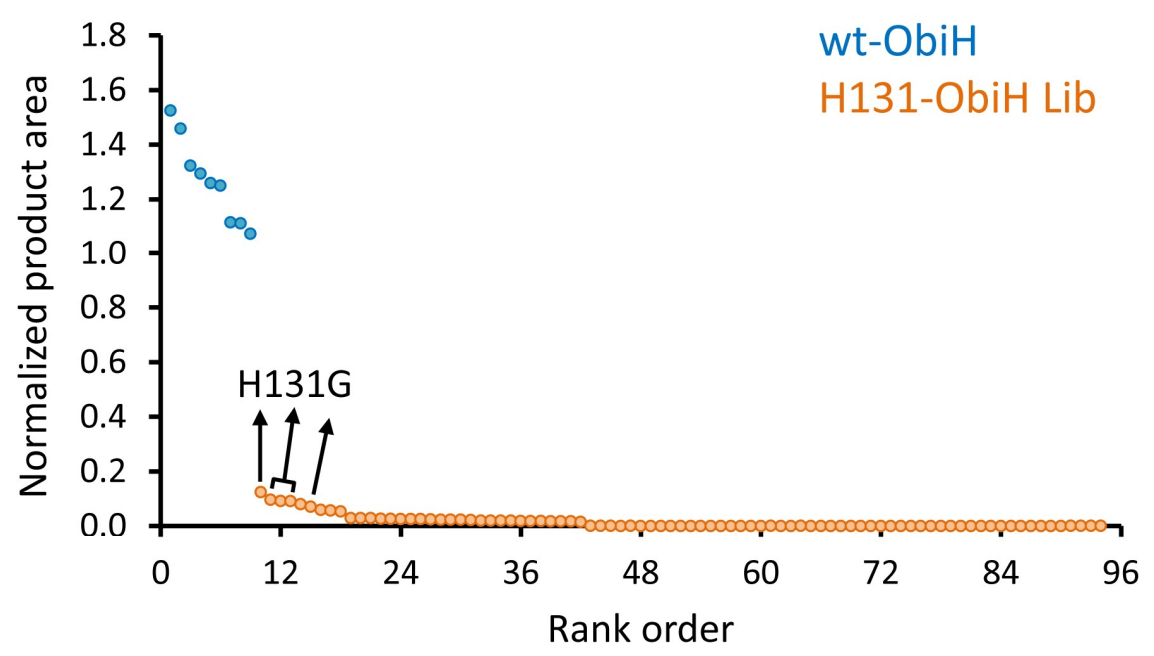

b

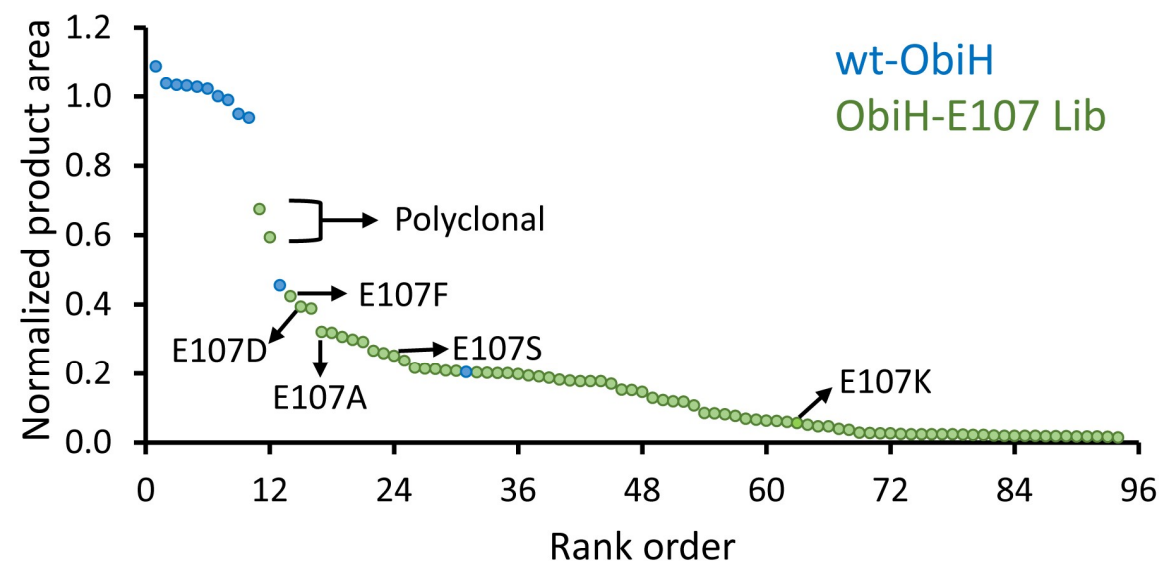

\section{C}

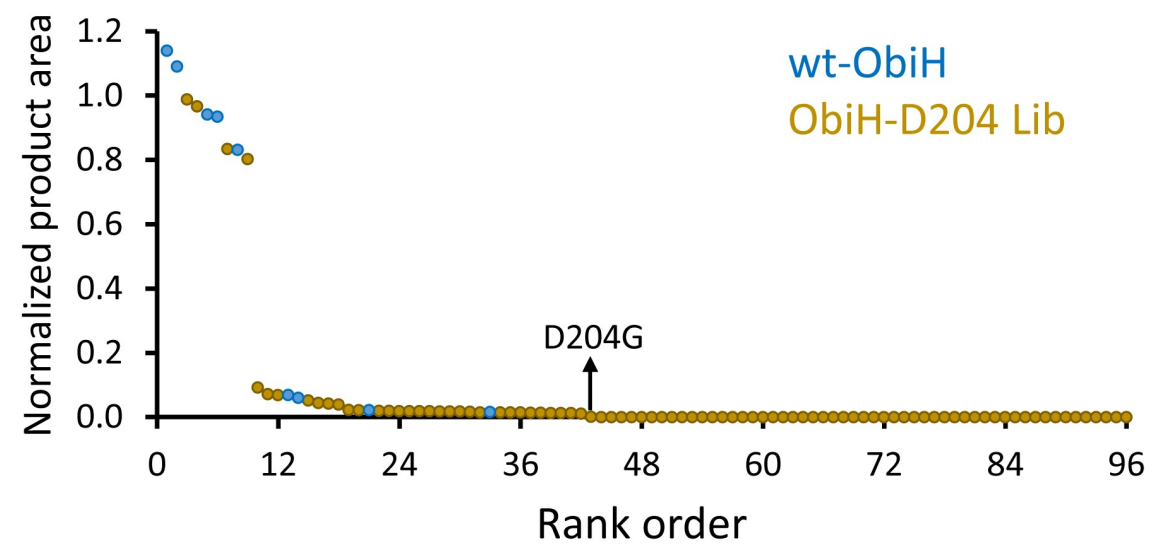

Figure S18. Activity profile of ObiH-131, ObiH-E107 and ObiH-D204 site saturation mutagenesis libraries. For each of the libraries, lysate supernatants were incubated with $75 \mathrm{mM}$ Thr and $15 \mathrm{mM}$ Biphyenyl-4-carboxaldehyde at $37^{\circ} \mathrm{C}$ for $16 \mathrm{~h}$. Then, proteins in the reaction mixture were precipitated 
by addition of acetonitrile. $1 \mathrm{uL}$ of Supernatant were injected into Acquity UPLC-MS (Waters) to quantitate the formation of b-hydroxy amino acid through UV@254 nm.

a

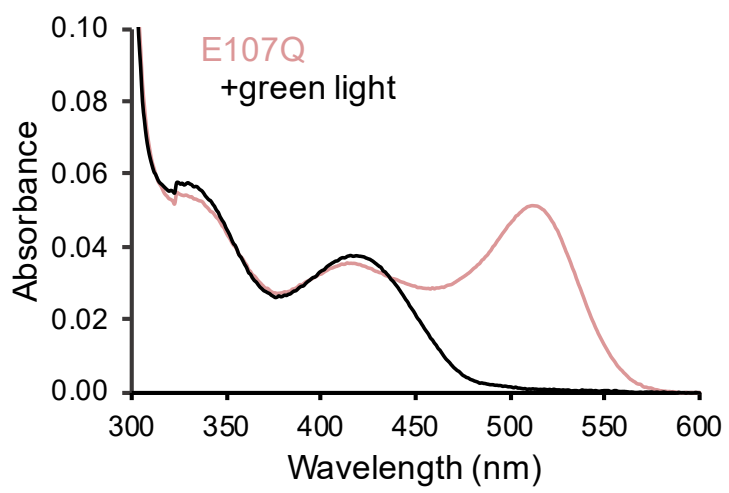

b

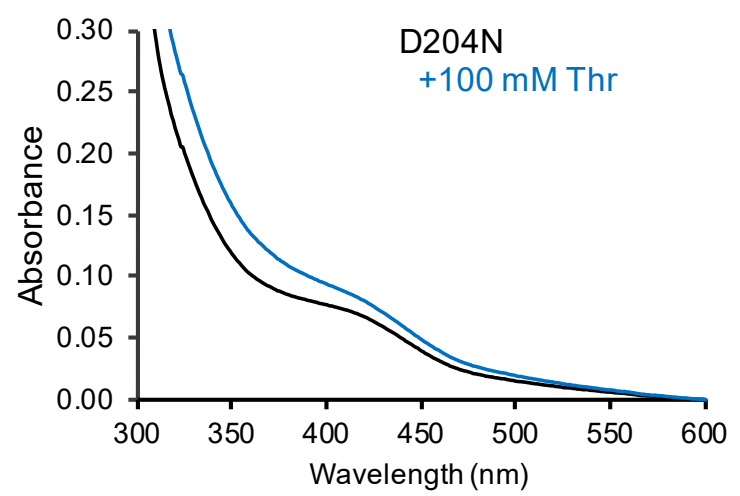

Figure S19. UV-vis spectra of ObiH-E107Q and ObiH-D204N. a) Absorbance spectra of purified E107Q-ObiH (pink) and phototreated E107Q-ObiH (black). b) Absorbance spectra of purified D204NObiH (black) and after addition of $100 \mathrm{mM}$ Thr (black).

a

\section{Gly standard curve}

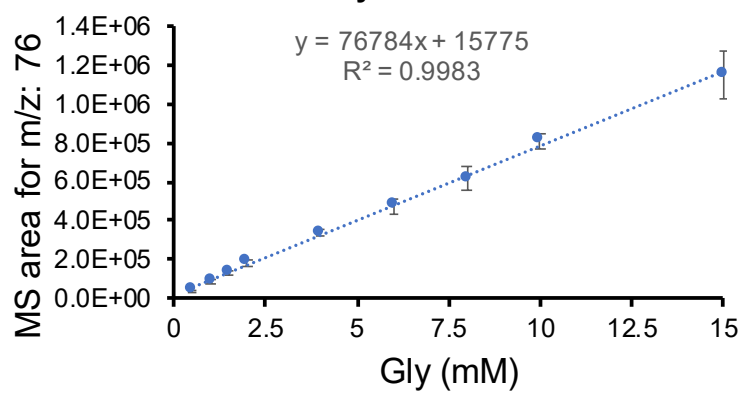

b

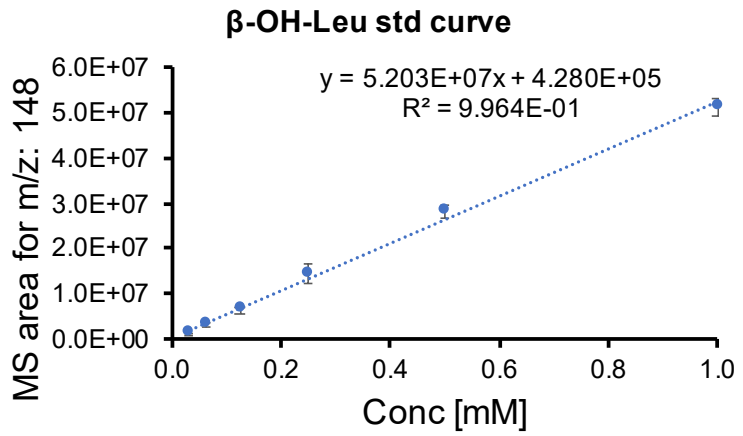

Figure S20. Standard curves for glycine and $\boldsymbol{\beta}$-OH-Leu. Product areas were measured for $\mathrm{M}^{+1}$ ion for each for glycine (a) $\beta$-OH-Leu (b) via UPLC-MS. 
Table S1. X-Ray crystallographic data collection and refinement statistics

\begin{tabular}{|l||c|}
\hline PDB ID & 7K34 \\
\hline Protein & $N$-His-ObiH \\
\hline \multicolumn{1}{|c|}{ Data Collection } \\
\hline Space group & P4 1 \\
\hline Cell dimensions $(\AA)$ & $\mathrm{a}, \mathrm{b}, \mathrm{c}=$ \\
& $118.6,118.6,130.0$ \\
\hline Cell angles & $\alpha=\beta=\gamma=90^{\circ}$ \\
\hline Wavelength $(\AA)$ & 1.03321 \\
\hline Beamline & APS $23-\mathrm{ID}-\mathrm{D}$ \\
\hline Resolution $(\AA)$ & $50-1.66$ \\
\hline Last bin $(\AA)$ & $(1.70-1.66)$ \\
\hline No. observations & 2826075 \\
\hline Completeness $(\%)$ & $100.0(100.0)$ \\
\hline $\mathrm{R}_{\text {pim }}$ & $0.058(0.827)$ \\
\hline CC $(1 / 2)$ & $0.996(0.450)$ \\
\hline $\mathrm{I} / \sigma \mathrm{I}$ & $6.9(1.0)$ \\
\hline Redundancy & $13.4(13.1)$ \\
\hline \multicolumn{1}{|c|}{ Refinement } \\
\hline Total no. of reflections & 200,497 \\
\hline Total no. of atoms & 14,557 \\
\hline Final bin $(\AA)$ & $(1.70-1.66)$ \\
\hline $\mathrm{R}_{\text {work }}(\%)$ & $21.2(32.6)$ \\
\hline $\mathrm{R}_{\text {free }}(\%)$ & $24.2(34.2)$ \\
\hline Average B factor $\left(\AA^{2}\right)$ & 27.2 \\
\hline $\begin{array}{l}\text { Ramachandran plot } \\
\text { Favored, \% }\end{array}$ & 97.5 \\
\hline Allowed, \% & 100.0 \\
\hline Outliers, \% & 0.0 \\
\hline & \\
\hline
\end{tabular}

Values in parenthesis are for the highest resolution shell. $\mathrm{R}_{\text {merge }}$ is $\Sigma|\mathrm{Io}-\mathrm{I}| / \Sigma$ Io, where Io is the intensity of an individual reflection, and $\mathrm{I}$ is the mean intensity for multiply recorded reflections. $\mathrm{R}_{\text {work }}$ is $\Sigma|| \mathrm{Fo}-$ $\mathrm{Fc} \| / \mathrm{Fo}$, where Fo is an observed amplitude and $\mathrm{Fc}$ a calculated amplitude. $\mathrm{R}_{\text {free }}$ is the same statistic calculated with a $5 \%$ subset of the data that was excluded from refinement. 
Table S2. Hydrogen bonding properties of PLP-N1 H-bond acceptors.

\begin{tabular}{|c|c|c|c|c|c|c|c|}
\hline \multicolumn{2}{|c|}{} & \multicolumn{2}{|c|}{$\begin{array}{c}\text { H-bond } \\
\text { Abundance }\end{array}$} & \multicolumn{4}{c|}{ H-bond Lifetimes } \\
\cline { 3 - 8 } \multicolumn{2}{|c|}{} & Average & StDev & Amp $_{\mathrm{C} 1}$ & $\boldsymbol{\tau}_{\mathrm{C} 1}$ (ps) & Amp p $_{\mathrm{C} 2}$ & $\boldsymbol{\tau}_{\mathrm{C} 2}$ (ps) \\
\hline \multirow{2}{*}{$\mathrm{E}$ (Ain) } & Glu107 & $63 \%$ & $30 \%$ & $42 \%$ & 5.13 & $58 \%$ & 0.96 \\
\cline { 2 - 8 } & Asp204 & $6 \%$ & $9 \%$ & $39 \%$ & 1.21 & $61 \%$ & 0.11 \\
\hline \multirow{2}{*}{ E(Aex ${ }^{\text {Thr }}$ ) } & Glu107 & $22 \%$ & $31 \%$ & $32 \%$ & 2.26 & $68 \%$ & 0.10 \\
\cline { 2 - 8 } & Asp204 & $48 \%$ & $41 \%$ & $43 \%$ & 2.26 & $57 \%$ & 0.27 \\
\hline
\end{tabular}

Abundance refers to the average percentage of time throughout a trajectory that a given H-bond acceptor was present. H-bond lifetime parameters were generated by fitting the corresponding continuous autocorrelation data to a biexponential function. "Amp $\mathrm{Cn}$ " refers to the contribution amplitude of a given exponential component, while $\tau_{\mathrm{Cn}}$ refers to the lifetime of the exponential component. 
NMR Spectra:

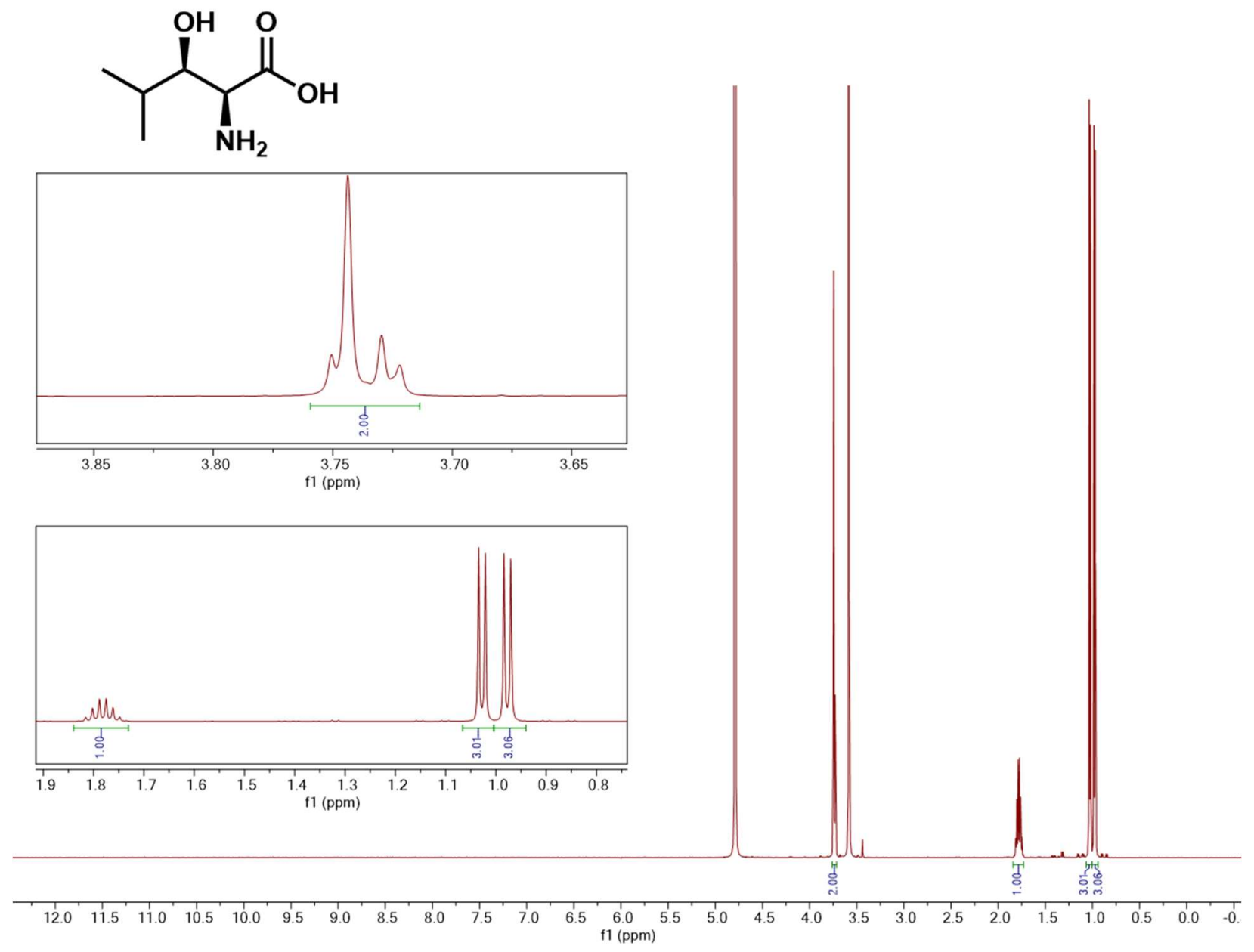




\section{References}

(1) Gibson, D. G.; Young, L.; Chuang, R.-Y.; Venter, J. C.; Hutchison, C. A.; Smith, H. O. Enzymatic Assembly of Overlapping DNA Fragments. Nat. Methods. 2009, 6 (5), 343-345.

Frisch, M. J.; Trucks, G. W.; Schlegel, H. B.; Scuseria, G. E.; Robb, M. a.; Cheeseman, J. R.; Scalmani, G.; Barone, V.; Petersson, G. a.; Nakatsuji, H.; Li, X.; Caricato, M.; Marenich, a. V.; Bloino, J.; Janesko, B. G.; Gomperts, R.; Mennucci, B.; Hratchian, H. P.; Ortiz, J. V.; Izmaylov, a. F.; Sonnenberg, J. L.; Williams; Ding, F.; Lipparini, F.; Egidi, F.; Goings, J.; Peng, B.; Petrone, A.; Henderson, T.; Ranasinghe, D.; Zakrzewski, V. G.; Gao, J.; Rega, N.; Zheng, G.; Liang, W.; Hada, M.; Ehara, M.; Toyota, K.; Fukuda, R.; Hasegawa, J.; Ishida, M.; Nakajima, T.; Honda, Y.; Kitao, O.; Nakai, H.; Vreven, T.; Throssell, K.; Montgomery Jr., J. a.; Peralta, J. E.; Ogliaro, F.; Bearpark, M. J.; Heyd, J. J.; Brothers, E. N.; Kudin, K. N.; Staroverov, V. N.; Keith, T. a.; Kobayashi, R.; Normand, J.; Raghavachari, K.; Rendell, a. P.; Burant, J. C.; Iyengar, S. S.; Tomasi, J.; Cossi, M.; Millam, J. M.; Klene, M.; Adamo, C.; Cammi, R.; Ochterski, J. W.; Martin, R. L.; Morokuma, K.; Farkas, O.; Foresman, J. B.; Fox, D. J. Gaussian 16, Revision C.01. Gaussian, Inc., Wallingford CT, 2016.

Van Rossum, G.; Drake, F. L. Python 3 Reference Manual; CreateSpace: Scotts Valley, CA, 2009.

(4) Virtanen, P.; Gommers, R.; Oliphant, T. E.; Haberland, M.; Reddy, T.; Cournapeau, D.; Burovski, E.; Peterson, P.; Weckesser, W.; Bright, J.; van der Walt, S. J.; Brett, M.; Wilson, J.; Jarrod Millman, K.; Mayorov, N.; Nelson, A. R. J.; Jones, E.; Kern, R.; Larson, E.; Carey, C. J.; Polat, \.Ilhan; Feng, Y.; Moore, E. W.; Vand erPlas, J.; Laxalde, D.; Perktold, J.; Cimrman, R.; Henriksen, I.; Quintero, E. A.; Harris, C. R.; Archibald, A. M.; Ribeiro, A. H.; Pedregosa, F.; van Mulbregt, P.; Contributors, S. 1. 0. SciPy 1.0: Fundamental Algorithms for Scientific Computing in Python. Nat Methods. 2020, 17 (3), 261-272.

Abraham, M. J.; van der Spoel, D.; Lindahl, E.; Hess, B.; GROMACS Development Team, GROMACS 5.1.2 Reference Manual 2016.

(6) Case, D. A.; Belfon, K.; Ben-Shalom, I. Y.; Brozell, S. R.; Cerutti, D. S.; Cheatham, III, T. E.; Cruzeiro, V. W. D.; Darden, T. A.; Duke, R. E.; Giambasu, G.; Gilson, M. K.; Gohlke, H.; Goetz, RHarris, A. W.; Izadi, S.; Kasava-jhala, K.; Kovalenko, A.; Krasny, R.; Kurtzman, T.; Lee, T. S.; LeGrand, S.; Li, P.; Lin, C.; Liu, J.; Luchko, T.; Luo, R.; Man, V.; Merz, K. M.; Miao, Y.; Mikhailovskii, O.; Monard, G.; Nguyen, H.; Onufriev, A.; Pan, F.; Pantano, S.; Qi, R.; Roe, D. R.; Roitberg, A.; Sagui, C.; Schott-Verdugo, S.; Shen, J.; Simmerling, C. L.; Skrynnikov, N.; Smith, J.; Swails, J.; Walker, R. C.; Wang, J.; Wilson, L.; Wolf, R. M.; Wu, X.; York, D. M.; Kollman, P. A. AMBER 2020. University of California, San Francisco. 2020.

Lindorff-Larsen, K.; Piana, S.; Palmo, K.; Maragakis, P.; Klepeis, J. L.; Dror, R. O.; Shaw, D. E. Improved Side-Chain Torsion Potentials for the Amber Ff99SB Protein Force Field. Proteins Struct. Funct. Bioinforma. 2010, 78 (8), 1950-1958.

Abraham, M. J.; Murtola, T.; Schulz, R.; Páll, S.; Smith, J. C.; Hess, B.; Lindahl, E. GROMACS: High Performance Molecular Simulations through Multi-Level Parallelism from Laptops to Supercomputers. SoftwareX 2015, 1-2, 19-25.

(9) Jorgensen, W. L.; Chandrasekhar, J.; Madura, J. D.; Impey, R. W.; Klein, M. L. Comparison of Simple Potential Functions for Simulating Liquid Water. J. Chem. Phys. 1983, 79 (2), 926-935.

(10) Martínez-Rosell, G.; Giorgino, T.; De Fabritiis, G. PlayMolecule ProteinPrepare: A Web Application for Protein Preparation for Molecular Dynamics Simulations. J. Chem. Inf. Model. 2017, 57 (7), 1511-1516.

(11) Dahanayake, J. N.; Gautam, D. N.; Verma, R.; Mitchell-Koch, K. R. To Keep or Not to Keep? The Question of Crystallographic Waters for Enzyme Simulations in Organic Solvent. Mol. Simul. 2016, 42 (12), 10011013.

(12) Hess, B.; Bekker, H.; Berendsen, H. J. C.; Fraaije, J. G. E. M. LINCS: A Linear Constraint Solver for Molecular Simulations. J. Comput. Chem. 1997, 18 (12), 1463-1472.

(13) Darden, T.; York, D.; Pedersen, L. Particle Mesh Ewald: An N·log(N) Method for Ewald Sums in Large 
Systems. J. Chem. Phys. 1993, 98 (12), 10089-10092.

(14) Bussi, G.; Donadio, D.; Parrinello, M. Canonical Sampling through Velocity Rescaling. J. Chem. Phys. 2007, $126(1), 014101$.

(15) Berendsen, H. J. C.; Postma, J. P. M.; Van Gunsteren, W. F.; Dinola, A.; Haak, J. R. Molecular Dynamics with Coupling to an External Bath. J. Chem. Phys. 1984, 81 (8), 3684-3690.

(16) Nosé, S. A Unified Formulation of the Constant Temperature Molecular Dynamics Methods. J. Chem. Phys. 1984, $81(1), 511-519$.

(17) Hoover, W. G. Canonical Dynamics: Equilibrium Phase-Space Distributions. Phys. Rev. A 1985, 31 (3), $1695-1697$.

(18) Parrinello, M.; Rahman, A. Polymorphic Transitions in Single Crystals: A New Molecular Dynamics Method. J. Appl. Phys. 1981, 52 (12), 7182-7190.

(19) Fairman, J.W., Jensen, M.M., Sullivan, A.H., Edwards, T.E., Lorimer, D. PDBID: 4OT8 - X-Ray Crystal Structure of Serine Hydroxymethyl Transferase from Burkholderia Cenocepacia Bound to PLP and Serine.

(20) Michaud-Agrawal, N.; Denning, E. J.; Woolf, T. B.; Beckstein, O. MDAnalysis: A Toolkit for the Analysis of Molecular Dynamics Simulations. J. Comput. Chem. 2011, 32 (10), 2319-2327.

(21) Gowers, R.; Linke, M.; Barnoud, J.; Reddy, T.; Melo, M.; Seyler, S.; Domański, J.; Dotson, D.; Buchoux, S.; Kenney, I.; Beckstein, O. MDAnalysis: A Python Package for the Rapid Analysis of Molecular Dynamics Simulations. In Proceedings of the 15th Python in Science Conference; SciPy, 2016; pp 98-105.

(22) Van Der Walt, S.; Colbert, S. C.; Varoquaux, G. The NumPy Array: A Structure for Efficient Numerical Computation. Comput. Sci. Eng. 2011, 13 (2), 22.

(23) Hunter, J. D. Matplotlib: A 2D Graphics Environment. Comput. Sci. Eng. 2007, 9 (3), 90-95.

(24) Kumar, S.; Rosenberg, J. M.; Bouzida, D.; Swendsen, R. H.; Kollman, P. A. THE Weighted Histogram Analysis Method for Free-Energy Calculations on Biomolecules. I. The Method. J. Comput. Chem. 1992, 13 (8), 1011-1021.

(25) Kille, S.; Acevedo-Rocha, C. G.; Parra, L. P.; Zhang, Z. G.; Opperman, D. J.; Reetz, M. T.; Acevedo, J. P. Reducing Codon Redundancy and Screening Effort of Combinatorial Protein Libraries Created by Saturation Mutagenesis. ACS Synth. Biol. 2013, 2 (2), 83-92. 